\title{
Clinical pharmacology and therapeutics
}

\author{
M.J. Kendall and R.C. Horton \\ Department of Medicine, Queen Elizabeth Hospital, Birmingham B15 2TH, UK.
}

\section{Introduction}

The combined subject Clinical Pharmacology and Therapeutics is concerned with all aspects of the drug treatment of disease. It therefore overlaps to a greater or lesser extent the areas of interest of all clinicians whose patients require drug treatment. It is also concerned with drug actions, drug development, drug assessment and drug administration. In addition, adverse effects, drug interactions and drug overdosage are within the province of the clinical pharmacologist.

In this review we have chosen to consider some of the main systems of the body and to highlight those aspects of therapy in which treatment has improved, where the impact of drugs for good or bad is becoming better understood or where advances in our understanding of drug actions are leading to hopes of better methods of treatment in the relatively near future.

In some instances we have attempted to draw attention to the recent advances, in others we have attempted to define the present position based on the progress made over the last few years. We have not tried to be comprehensive: rather we have chosen some areas of therapeutics where we feel that the advances in knowledge made by the specialist should be presented to the non-specialist with the suggestion that his or her therapeutic approach may need to undergo a little reconsideration.

We also include a piece highlighting the impact of clinical trial methodology on various treatments under the broad heading of alternative medicine. Areas such as adverse reactions, interactions, pharmacokinetics and toxicology will not be dealt with specifically in this review.

\section{Cardiovascular pharmacology}

There have been a large number of advances in the management of cardiovascular disease in general and in the prevention and treatment of myocardial infarction in particular. Assessments of the impact

Correspondence: M.J. Kendall. M.D., F.R.C.P. of thrombolytic agents on the acute infarct patient, the role of aspirin as a prophylactic agent in relation to ischaemic heart disease ${ }^{1}$ and the continuing interest in newer antihypertensive agents have been the subject of reviews published elsewhere. We have chosen in this section to consider three quite different aspects of therapeutics which appear to be having a major impact on the development and consequences of ischaemic heart disease. These are the recent advances in the management of heart failure, the increasing use of lipid lowering drugs and hormone replacement therapy.

\section{Heart failure}

Two of the major areas of interest in the therapeutics of chronic heart failure have been a reappraisal of the use of inotropic agents and the precise indications for and benefits of angiotensin converting enzyme (ACE) inhibitors. For each drug the clinically relevant end points should be seen as more important than the improvements in abstract haemodynamic variables alone. Thus we should focus particularly upon improvement of clinical symptoms with prolonged exercise tolerance and reduction in NYHA class, resolution of the clinical signs of heart failure and finally a reduction in a mortality including sudden death.

\section{Positive inotropes}

The traditional use of digoxin as an inotropic agent in heart failure patients who are in sinus rhythm was questioned in the 1970 s by studies showing that on digoxin withdrawal there were few adverse long term clinical effects. ${ }^{2}$ Moreover, digoxin appeared to have poor haemodynamic value acutely ${ }^{3}$ and its proarrhythmic effects ${ }^{4}$ were raised as a potential cause of further morbidity and mortality.

However, there has been a tendency to ignore some of the known facts about digoxin. It has much broader physiological effects than merely acting as a positive inotrope or slowing atrioventricular conduction. Extensive in vivo animal studies have 
shown that it has potent neurally mediated effects on the cardiovascular system. It has excitatory effects on baro- and chemoreceptors leading to vasodilatation and a fall in arterial pressure. It stimulates cardiac mechanoreceptors, facilitates vagal effects and is able to antagonize sympathetic input to the heart. All of these influences lead to a reduction in afterload and so are beneficial in heart failure. ${ }^{5}$ These effects have been neglected and now that other agents are being investigated in patients, digoxin has undergone a signficant reassessment. For example, controlled studies do show a beneficial haemodynamic effect of digoxin therapy. ${ }^{6}$

Furthermore, the clinical benefit of digoxin appears to be more firmly established. The Captopril-Digoxin Multicentre Research Group ${ }^{7}$ showed a significant increase in left ventricular ejection fraction and the German and Austrian Xamoterol Study Group ${ }^{8}$ found that digoxin produced significant improvement in the symptoms and signs of heart failure together with a reduction in the cardiothoracic ratio. These are not simply short term effects. The captopril and xamoterol studies ran over 6 and 3 months respectively. Guyatt et al., in a randomized study, examined digoxin versus placebo in 20 patients with heart failure of variable severity. ${ }^{9}$ A clear benefit was demonstrated in terms of improving dyspnoea, exercise capacity and reducing deterioration in heart failure. They attempted to analyse the predictors of this response and found that a third heart sound, cardiothoracic ratio of greater than 0.55 , together with jugular venous pressure of $6 \mathrm{~cm}$ or more and poor exercise capacity were all associated with a beneficial response to digoxin. It was noted that the drug level at which digoxin proved therapeutic was higher than conventionally recognized with a mean of $1.75 \pm 0.45 \mathrm{nmol} / 1$ (range $1.54-2.56 \mathrm{nmol} / \mathrm{l})$.

Alternatives to cardiac glycosides have been sought but few have been clinically successful. Milrinone combines a positive inotropic effect with a vasodilatory action. Though found to have definite beneficial effects in heart failure - increasing exercise tolerance and reducing the frequency of decompensation - up to $20 \%$ of patients on milrinone deteriorate, an adverse trend in mortality is found (though non-significant) and the frequency of ventricular arrhythmias is increased. ${ }^{10}$ Moreover, in this study (involving 230 patients in a double-blind 12 week protocol) digoxin caused deterioration in only $3 \%$ of patients, increased left ventricular ejection fraction (unchanged with milrinone) and had no effect on the frequency of arrhythmias.

Enoximone is a type III phosphodiesterase inhibitor and acts by increasing intracellular cAMP. This promotes myocardial contractility and arterial vasodilatation thereby reducing afterload. Again the clinical benefits are apparent in small studies: NYHA class and symptoms are improved and exercise capacity is increased. ${ }^{11}$ However, mortality appears to remain high, a proarrhythmic effect has been demonstrated and symptomatic tolerance develops after three months of therapy. Despite these drawbacks it may well prove useful as a bridge for short term cardiac support in patients awaiting transplantation. ${ }^{12}$

The difficulties of inotropic agents centre around their proarrhythmic actions and tendency to increase myocardial oxygen consumption. These problems may be overcome by partial $\beta_{1}$ agonists such as xamoterol. These drugs act as agonists to the $\beta_{1}$ receptor when sympathetic tone is low but antagonists when tone is high and therefore prevent the adverse effects of excessive sympathetic activation in heart failure such as tachycardia, and renin-angiotensin activation. In patients at rest they can improve contractility, reduce diastolic wall stress and left ventricular filling pressure. ${ }^{13}$ In exercise they reduce myocardial ischaemia and maintain cardiac output. ${ }^{14}$ In clinical terms this means an improvement of exercise capacity by $33 \%$ and reduction in the symptoms and signs of failure. ${ }^{8}$ Their specific indication is in mild-moderate failure (NYHA II, III) principally due to ischaemic heart disease and in situations of echocardiographically or angiographically proven diastolic dysfunction. They should not be used in severe heart failure where haemodynamic stability is strongly dependent upon activation of the sympathetic system.

The place of other inotropic agents, such as the dopamine (receptor subclass 1) agonists, L-dopa, dopexamine and fenoldopam, remains to be fully evaluated but appears to offer encouraging signs that alternatives to digitalis may be available in the future.

\section{ACE inhibitors}

The early use of ACE inhibitors in severe heart failure is now clearly recognized as a means of reducing mortality in this progressive condition. In the patients studied in the CONSENSUS trial the mean dose of frusemide was $200 \mathrm{mg}$ and one third were using other forms of vasodilators, e.g. nitrates. One year follow-up confirmed a highly significant mortality benefit. ${ }^{15}$ This effect may not be a property of ACE inhibition per se but reflects the value of vasodilatation as shown in a similar mortality reduction using nitrates and hydralazine. $^{16}$

Moreover, captopril is of confirmed value in mild heart failure. In a study of 300 patients with predominantly NYHA class II symptoms captopril added to diuretic therapy significantly increased 
exercise time, reduced NYHA class and reduced incidence of ventricular ectopic activity as compared to placebo. ${ }^{7}$

Cardioprotection remains the elusive goal of therapeutics for myocardial infarction (MI). While thrombolytic agents improve mortality within a 24-hour period after onset of chest pain (which persists for up to one year), reversing disease progression in the longer term remains problematic. Calcium antagonists are of no benefit while beta-blockers are contraindicated in a large group of patients. ACE inhibitors may bridge this gap.

Pfeffer et al. were able to show in a randomized double-blind placebo controlled study with a one year follow-up in 59 patients that captopril therapy significantly reduced left ventricular end diastolic volume and left ventricular filling pressure. ${ }^{17}$ These patients had sustained their first anterior MI and captopril was initiated at a mean of 20 days post-infarct. The target dose was $25 \mathrm{mg}$ three times a day for in-patients and $50 \mathrm{mg}$ three times a day for outpatients. In addition, a subgroup with an occluded left anterior descending coronary artery were at high risk of ventricular dilatation and this was prevented by captopril. Exercise capacity was also increased in the captopril group. Hence, ventricular dilatation which indicates systolic dysfunction and is a major adverse prognostic indicator for acute MI appeared to be preventable with captopril treatment in this small study. A large scale investigation of the role of captopril in this situation is currently in progress.

Captopril also has a proven anti-arrhythmic effect reducing the incidence of ventricular ectopics, couplets and salvoes in chronic therapy ${ }^{18}$ as well as inhibiting the generation of reperfusion arrhythmias in isolated rat hearts. ${ }^{19}$ Two questions arise. Firstly, why?, and secondly, can this be translated into any mortality benefit? The latter question awaits confirmation but some interesting clues exist as to its possible mechanism of action. Captopril is unique to the ACE inhibitors as a free radical scavenger in vitro due to its sulphydryl group. ${ }^{20,21} \mathrm{~A}$ preliminary report confirms this in 25 patients with congestive cardiac failure who had documented increased free radical activity. ${ }^{22}$

The dynamics of sodium and water retention in heart failure are now more clearly understood and drugs promoting natriuresis may have a benefit in offloading the heart. ${ }^{23}$ Atrial natriuretic peptide is a novel route through which a beneficial effect may be seen. Promoting its activity by inhibiting an endopeptidase (its principal degradative enzyme) increases natriuresis and diuresis. ${ }^{24}$ Further clinical trials are awaited with interest since this may represent a direct route for influencing deleterious neuroendocrine reflex activation in heart failure.
Overall therefore in the practical management of heart failure, patients should be broadly divided into two groups. Those with class II symptoms (symptomatic during ordinary activity) should initially be treated with diuretics. The choice of a second agent depends on further assessment. If the patient has a third sound with cardiomegaly, digoxin may be indicated; if the patient has predominantly diastolic dysfunction proven echocardiographically then a drug like xamoterol may be appropriate. For the majority of patients with such mild symptoms, however, an ACE inhibitor would be the second agent chosen.

In class III and IV failure (symptomatic with minimal activity or at rest) the treatment schedule is clearer. Diuretics should be followed by an ACE inhibitor (reduced mortality) and patients may benefit from digoxin. ${ }^{25}$

\section{The management of hyperlipidaemia}

Over the last few years there appears to have been an exponential increase in the interest in and papers on plasma lipids. Although the importance of hyperlipidaemia as a risk factor in coronary artery disease has been appreciated for many years, the development of a range of more effective lipid lowering drugs ${ }^{26,27}$ and in particular the HMG CoA reductase inhibitors ${ }^{28-30}$ has made the subject of serum lipid reduction a matter of considerable commercial importance. The result has been a rapid growth in sponsored research, publications, meetings and journal supplements.

\section{Lipid measurements and classifications}

High concentrations of low density lipoprotein (LDL) are associated with increased risk of coronary heart disease. ${ }^{32,33}$ Unfortunately precise measurements of this fraction are difficult and therefore since LDL represents $70 \%$ of the total cholesterol the latter is a useful guide to the patients lipid status and hence prognosis. A better assessment follows from measuring high density lipoprotein (HDL) and subtracting this from the total cholesterol. This becomes more precise if the triglyceride concentration (all measurement in $\mathrm{mmol} / \mathrm{l}$ ) is included by use of the following formula ${ }^{34}$

$\left(\mathrm{LDL}=\right.$ total cholesterol $-\left(\mathrm{HDL}+\frac{\text { triglyceride }}{2.2}\right)$

In the future, apolipoprotein ratios may be useful (B/A representing the principle apolipoproteins of LDL and HDL respectively) together with apo E phenotyping. ${ }^{31}$.

It is recommended that blood for cholesterol be taken in the non-fasting state preferably with the 
patient resting quietly and with no venous compression at the time the blood sample is withdrawn.

On the basis of the results of the above measurements it is possible to categorize patients into groups within defined classifications or treatment strategies. However, for the non-expert wishing to improve the patients prognosis in relation to ischaemic heart disease it is probably enough to note simply that (a) a high total cholesterol is bad, (b) the prognosis is adversely influenced by increasing LDL and decreasing HDL and (c) the triglyceride concentration not associated with a raised cholesterol merits attention as a cause of pancreatitis and as a possible associate of obesity, alcohol excess and diabetes but does not merit treatment as a coronary risk factor.

\section{Plasma concentrations and risk}

The concept of a normal range is not really applicable to the serum cholesterol. Most individuals fall within the range of $2-9 \mathrm{mmol} / \mathrm{l}$ and there is an approximately Gaussian distribution. The mortality rate in individuals with low cholesterol, below $5 \mathrm{mmol} / 1$, is increased because they include some patients with carcinomas or other disorders. Above $5.2 \mathrm{mmol} / \mathrm{l}(200 \mathrm{mg} / \mathrm{dl})$ the coronary heart disease (CHD) mortality rate starts to increase and increases markedly above $6.5 \mathrm{mmol} / 1$ (or $250 \mathrm{mg}$ / dl)..$^{34}$

Countries with a low incidene of CHD such as Japan have populations with serum cholesterol levels at the lower end of the range. In the United Kingdom which has a high incidence of CHD well over half the population have cholesterol levels over $5.2 \mathrm{mmol} / 1,25 \%$ over $6.5 \mathrm{mmol} / \mathrm{l}$ and $3-5 \%$ have grossly elevated values in the $8-9 \mathrm{mmol} / \mathrm{l}$ range.

\section{Management plan}

The first important differentiation one must make is that of primary and secondary prevention. It is unfortunate that no evidence exists to support the reduction of serum cholesterol following a myocardial infarction..$^{35}$ All treatment that we shall discuss focusses on primary prevention only. Whatever is done about the serum lipids should be carried out as part of a total strategy of multiple coronary risk factor intervention. Those factors which can be corrected, such as smoking habit and hypertension, should be corrected. Those which cannot, such as family history and being male, should be seen as factors which provoke the doctor and patient to correct the raised lipids more rigorously.

The management strategy for the patient with a raised serum cholesterol can be summarized as: (1) correct correctable coronary risk factors;
(2) cholesterol concentration $5.3-6.5 \mathrm{mmol} / \mathrm{l}$ : dietary advice with reinforcement, encouragement and follow-up; (3) cholesterol concentration $>6.5 \mathrm{mmol} / \mathrm{l}$ : dietary advice with recourse to drug therapy if no improvement after 3 months; (4) cholesterol concentration $>8 \mathrm{mmol} / \mathrm{l}$ : immediate drug therapy with dietary advice and careful follow-up.

\section{Drug treatment}

In considering the drug treatment of hyperlipidaemia it seems reasonable to predict that the data available will increase markedly and the patterns of drug use will change over the next year or two. Accordingly we propose to consider what the doctor might expect of the drug in relation to a particular compound and then to review very briefly the extent to which some of the currently available compounds match our requirements.

These compounds may be given to large numbers of patients who are currently well and treatment may be required for long periods. The patient population will include patients who are overtly at risk of developing the manifestations of coronary artery disease and because of this may be taking certain classes of drugs.

Facing the drug company representative who wants to recommend a lipid lowering drug we might reasonably ask (1) Mode of action: How does it work? (2) Efficacy: Is it effective? (a) Does it decrease LDL and triglycerides and increase HDL? (b) Has it been shown to reduce the clinical manifestations of coronary artery disease in proper double blind clinical trials? (c) Because it does reduce CHD and because it has no other adverse effects does it reduce total mortality? (3) Tolerability: (a) Specific - will it adversely affect the coronary-prone? It should have no proarrhythmic effects, or give hypokalaemia. It should not be a vasoconstrictor, negative inotrope or have adverse effects on diabetes. (b) Non-specific - will it upset the patient? (4) Safety: Are there any long term effects of blocking the delivery of an essential component of cells and a source of energy? What is the evidence of long term safety? (5) Simple regimen. (6) Acceptable cost. (7) Pharmaceutical and pharmacological - Reasonable half life; long shelf life; no interactions with other drugs taken by the coronary-prone patient.

The drugs which are available have to be measured against the above criteria and the decision about which drug to use will depend on how well they meet the criteria and the problem posed by the particular patient. The drugs fall into one of six main groups: (1) ion exchange resins; (2) fibric acid derivatives; (3) HMG CoA reductase inhibitors; (4) fish oils; (5) probucol; (6) nicotinic acid analogues. 
Several reviewers have commented on the important features of the drugs in each of the above groups. ${ }^{27,34}$ Fish oils have been used predominantly to reduce serum triglycerides. ${ }^{34}$ Probucol is effective but unpredictable and reduces both HDL and LDL. ${ }^{34}$ As with all the lipid lowering agents work on its mode of action is continuing. ${ }^{36}$ Nicotinic acid is a potent lipid lowering agent which lowers LDL and triglycerides and may increase HDL ${ }^{37}$ However, side effects, particularly flushing and itching, are common, ${ }^{37}$ although newer precursor agents such as acipimox reduce these.

The three other classes of drug merit more attention.

1. Bile acid sequestrant resins - this group of drugs have been in use for several years. ${ }^{27,37}$ They are not absorbed and reduce cholesterol by binding to and preventing the reabsorption of bile acids. The result is increased production of bile acids which is achieved by increasing the hepatic uptake of LDL, thereby reducing plasma LDL. HDL and triglycerides may increase a little. The adverse effects are constipation, gastrointestinal discomfort and impaired absorption of other food substances and drugs which bind to the resin. Up to 4 sachets need to be taken daily and these drugs are relatively expensive.

Cholestyramine was the drug used in the lipid research clinics study which was reported in $1984 .^{38}$ It showed that over 7 years, in middle aged hyperlipidaemic males who are prescribed 6 sachets daily, there was a $9 \%$ fall in serum cholesterol and a $19 \%$ decrease in CHD risk.

2. The fibrates include bezafibrate, clofibrate and gemfibrozil. Clofibrate and gemfibrozil have been subjected to large scale clinical trials. The clofibrate WHO trial showed a $9 \%$ reduction in cholesterol and a reduction in coronary events. ${ }^{39}$ However, there was also an increase in gall stones and all cause mortality which left clofibrate under a cloud. Gemfibrozil was studied in the Helsinki Heart Study in which 4081 symptomatic middle aged men with a 'primary dyslipidaemia' were randomized to receive the active drug $600 \mathrm{mg}$ twice daily or placebo using a randomized double blind technique. $^{33,40}$ Whilst there were no major changes in lipids in those on placebo, gemfibrozil increased HDL and reduced LDL, non-HDL cholesterol and triglycerides. The beneficial impact on serum lipids was associated with an improved cumulative rate of cardiac end points of 27.3 as against 41.4 per 1000 in the placebo group - a significant effect. There was no difference in overall mortality because the numbers studied were too small but there was no evidence that gemfibrozil increased the risk of developing other disorders particularly cancer.

The mechanism by which the fibrates achieve the improvement in serum lipids is not absolutely clear and it is likely that the different members of this group act in slightly different ways. They are fairly well tolerated making compliance less likely to be a problem than with the resins. ${ }^{35}$ In addition they are less expensive than the resins but they are not cheap.

3. HMG CoA reductase inhibitors are inhibitors of 3 hydroxy-3 methyl glutaryl-coenzyme A, the rate limiting enzyme in the synthesis of cholesterol. ${ }^{28-30}$ They are very effective cholesterollowering agents and are much more powerful in this regard than any of the other hypolipidaemic drugs. The assumption is that they will dramatically reduce the risk of coronary artery disease and the hope is that they will not have other unwanted effects. The enthusiasts are moving forward rapidly clinging to the assumption and the hope, the more cynical (perhaps the more scientific) are awaiting the evidence.

There can be little doubt that the commercial pressures to encourage doctors to prescribe the HMG CoA reductase inhibitors will be great. Many doctors will be confused about their role in the management of hyperlipidaemia but over the next year or so the rival merits of these agents and the other groups mentioned above will have to be sorted out. At the moment it would be difficult to produce a strategy for the drug treatment of lipid disorders which would gain universal acceptance.

No data exist to show that treatment of hyperlipidaemia for a few years produces a reduction in overall mortality. However, the 15 year mortality of the Coronary Drug Project now clearly shows a significant fall in total mortality, the first to have been shown with any lipid lowering agent. ${ }^{41}$ Reduction in coronary events is demonstrated with both cholestyramine and gemfibrozil but not HMG CoA reductase inhibitors as yet. The assumption that it is the reduction in cholesterol concentration alone which produces benefit requires caution as shown with the WHO clofibrate study. Thus no data are available to support treatment with HMG CoA reductase inhibitors as a definite means of reducing either cardiovascular or overall mortality. Currently, because of their proven long term beneficial effects, nicotinic acid, perhaps as acipimox to reduce side effects, or gemfibrozil which is better tolerated than other agents, might be considered the agents of choice in primary prevention. Clearly the newer agents are to be welcomed but they will need to show that they are superior to the older drugs in terms of their clinical efficacy.

This cautionary note does not imply any doubts about the lipid hypothesis. We accept that the correction of hyperlipidaemia by the most effective agents may prove to be the optimum therapy but 
only if long term follow-up demonstrates a low incidence of unacceptable adverse effects.

\section{Hormone replacement therapy (HRT) and the car- diovascular system}

A leading article in the British Medical Journal in June 1989 was entitled: "Hormone replacement therapy - deserves wider use". ${ }^{42}$ In it Belchetz reviewed briefly the value of HRT in relation to control of menopausal symptoms, its impact on cardiovascular disease and bone density, and referred to the potential risks of malignancy and how these may be reduced. Each aspect has provoked an enormous literature and it is therefore relatively easy for the non-specialist to become overwhelmed. As a result the medical profession may be overcautious and uncertain about the use of this potentially very effective form of therapy. Oestrogen replacement therapy may save between $250-280$ lives per 100,000 per year. ${ }^{43}$

The beneficial effects of HRT on vasomotor symptoms, insomnia and postmenopausal problems of the lower genital tract are well documented and widely accepted..$^{42} \mathrm{~A}$ recent study on peripheral blood flow confirmed the peripheral circulatory abnormalities in flushing women and demonstrated the benefit of oestrogen replacement therapy.$^{44}$ Studies on psychological symptoms have been more difficult to perform but seem to show that HRT is useful.

The longer term benefits in relation to postmenopausal osteoporosis and the tendency to develop fractures seems to be well established. Notelovitz ${ }^{45}$ has written a useful review of this subject explaining its complexity and the many aetiological variables involved. In addition Hammond and Maxson include a section on osteoporosis in their review of oestrogen replacement therapy ${ }^{46}$ and underline the magnitude of the problem in terms of the frequency of fractures particularly vertebral crush fractures $(25 \%$ of Caucasian women over 60), the risks from hip fractures occurring in the elderly and the overall hospital costs. Hormone replacement therapy protects against fractures of the wrist, ${ }^{47}$ spine $^{48}$ and hips. ${ }^{42.47-49}$

The concern over the possibility of increasing the incidence of carcinoma is readily understood. Unopposed oestrogen therapy given to women with a uterus does increase the risk of endometrial carcinoma ${ }^{50-52}$ Cyclical progestogen therapy given in addition produces withdrawal bleeds but appears to abolish the cancer risk..$^{42}$ The impact of HRT on breast cancer risk is still debated..$^{42,50,53}$ Serious concern has now been raised over the risk of breast cancer from a recent Swedish study. ${ }^{54}$ This prospective study examined over 23,000 women on
HRT and compared them to a group in the same geographical area. The study found no increased risk of breast cancer in the population as a whole but sub-group analysis revealed major differences. Firstly, in those treated with oestradiol for 9 years there was an increased risk of 1.8 times in developing breast cancer. Secondly, this risk rose to fourfold in those on treatment with oestradiol and a progestagen for 4 years. This study conflicts with others $^{55}$ and there are methodological problems in its analysis. The finding with combined oestrogen and progestagen treatment was in 10 patients only with wide confidence intervals. Moreover, the oestrogen preparation used is one uncommonly prescribed in the United Kingdom.

The potential impact of HRT on osteoporosis and on female malignancies would be relatively small compared with either a beneficial or detrimental effect on cardiovascular disease, particularly coronary artery disease (CAD). Initially because of the potential adverse effects of the oral contraceptives on cardiovascular mortality and morbidity ${ }^{56}$ (even though the risks are extremely small), it seemed possible that HRT might increase the risk of CAD in post-menopausal females. However, although a study from Framingham ${ }^{57}$ did suggest an adverse effect of HRT, other studies have yielded results ${ }^{58-62}$ which taken together strongly suggested a positive prophylactic role for oestrogen therapy in relation to CAD. More recent results have confirmed this conclusion and have added to our understanding of the possible mechanisms.

The lipid research clinics follow-up study ${ }^{63}$ followed a cohort of 2270 white women over a period of 8.5 years. There were 44 deaths due to cardiovascular disease in the 1677 non-users of oestrogen $(2.62 \%)$ and six in the 593 users $(1.01 \%)$. These were carefully examined for selection bias, and other risk factors, but finally the authors concluded that oestrogen therapy conferred a relative risk of $0.42(95 \%$ confidence limits 0.13 to 1.10$)$. They also demonstrated that the most likely explanation for the beneficial effect was an increase in HDL.

The so-called Walnut Creek Study ${ }^{64}$ involved a 10-13 year follow-up of 3437 women. This study was different from others in that some of the women were relatively young adults 'at the time of entry' and those on oestrogen showed a lower all cause mortality. However, the beneficial effects of oestrogen therapy on cardiovascular disease shown in previous studies were confirmed in this study.

A rather novel approach to assessing the impact of HRT on coronary arteries was to examine the results of angiography on women on the Milwaukee cardiovascular data registry. ${ }^{65}$ This study involved 933 post-menopausal women who required coronary angiography for accepted clinical reasons. However, by definition this was a selected population. It contained 154 oestrogen 
users and 779 non-users who were comparable in terms of risk factors except that the users had a significantly higher proportion of smokers (20.9 vs $13.4 \%)$. The angiograms were rated by experienced cardiologists who were unaware of the patients' coronary risk factors or oestrogen consumption. They found a signficantly lower occlusion score in the oestrogen users. Of further interest was the tendency for occlusion scores to increase with advancing age in the non-users and to decrease in the users. The users also had signficantly more favourable HDL and total cholesterol/HDL cholesterol ratio scores.

Although some studies have not shown any benefit, ${ }^{66}$ the consensus appears to be that HRT significantly reduces the incidence of coronary heart disease. Further, the potential impact on mortality and morbidity which could result from this cardioprotective effect could be considerable.

The mechanisms involved are probably complex and certainly not fully understood. A positive effect on serum lipids is likely to be an important factor. ${ }^{63,65,67,68}$ HRT does not seem to increase (and may slightly lower) blood pressure, ${ }^{69}$ does not adversely affect clotting factors ${ }^{70,71}$ nor does it produce carbohydrate intolerance. ${ }^{72}$ In conclusion, the benefits from HRT appear convincing and despite recent evidence, there is no statistically convincing data linking HRT to breast cancer.

\section{Asthma}

\section{Mortality}

The impetus for development of further antiasthma medications derives mainly from epidemiological data showing that there was a gradual rise in mortality in asthmatic patients from $1970-72$ up to $1982-84 .^{73}$ The most publicised reports are from New Zealand where there was a superimposed mortality peak in the late 1970 s. Thus, the mortality per 100,000 of the New Zealand population was $1.3,4.2$ and 1.85 for 1974 , 1979 and 1985 respectively. ${ }^{73}$ No such dramatic change has been reported elsewhere and the reasons for this peak in particular and the gradual rise in general are uncertain.

In considering why mortality continued to rise despite apparent improvement in available drugs much concern has focussed on $\beta_{2}$-agonists. ${ }^{74}$ There is now evidence that they may actually lead to adverse effects on the primary underlying problem in asthma - that is, bronchial hyperresponsiveness. Thus, after regular long term $\beta_{2}$ agonist treatment there is, during the 24 hours after stopping treatment, a hyperreactivity or hyperresponsiveness of bronchial smooth muscle and hence the protection conferred via bronchodilatation is partly lost on recommencing treatment. ${ }^{75}$ This rebound in smooth muscle reactivity will clearly lead to clinical exacerbations and may contribute to the worsening clinical problem. ${ }^{74}$

Moreover, a major study has now been published directly implicating fenoterol as the agent responsible for the New Zealand mortality peak in the late 1970s. ${ }^{76}$ The wider implications of this study, if accepted, are serious. It was a case control study to determine whether fenoterol by metered dose inhaler (MDI) led to an increase in risk of death in patients and asthma. It was based on two observations. First, that this drug was introduced in 1976, the same year mortality began to rise and that by 1983 it represented $30 \%$ of the total MDI $\boldsymbol{\beta}_{2}$-agonist market in New Zealand compared to $5 \%$ elsewhere in the world. Second, that in the New Zealand mortality survey, $50 \%$ of deaths were associated with fenoterol use although fenoterol represented only $25 \%$ of total sales.

From reports on 271 asthma deaths, a case group of 125 aged 5-45 years was selected because the diagnosis of asthma is made more reliably in children and young adults. The control group were asthma patients who recovered and left hospital during the period in which the above asthma deaths occurred. The diagnosis of asthma was made from hospital coding, 4 controls were selected per case and were matched for age and ethnic group.

Information on drug treatment was obtained in two ways. In cases, prescribed treatment (not drug use in the preceding 24 hours) was documented from a GP questionnaire on regular medication. In controls, hospital notes were used. Though data collection was different in the two groups the authors attempted to demonstrate that there was no bias by two validation exercises.

The results of this study demonstrated that the relative risk of death using MDI fenoterol was 1.55 , the risk being greater for those aged less than 20 . This was estimated to represent $40 \%$ of the excess mortality. This is the first major study of drug treatment in asthma mortality and has been strongly criticized ${ }^{77,78}$ and equally vigorously defended. ${ }^{79}$

Firstly, the study examines the prescribed, longterm treatment of patients while in the discussion they invoke acute toxic effects of $\boldsymbol{\beta}_{2}$-agonists as a potential explanation. Thus, in order to provide data to fit with their conclusion they should have examined treatment taken immediately prior to the final attack. This could have been obtained from friends or relatives of the asthmatic victim. Although this would certainly have been the ideal, it is practically impossible to obtain this data and families are unreliable in this respect. Furthermore, the investigators argue that it is reasonable to assume that the patient uses acutely what has been prescribed chronically. 
Secondly, there were problems over control subjects. There is concern that those derived from hospital records may have been less severe and that in any case severity was based on markers of chronicity, for example, taking oral steroids or admission in previous 12 months, as opposed to markers of severity of the final attack. However, the first criticism is purely subjective and the second may be missing the point, which is, that long term treatment may be contributory to mortality in terms of, for example, increased bronchial hyperresponsiveness or cardiotoxicity.

Finally, mortality has now fallen while fenoterol sales have remained static. Although sales figures may have been a useful pointer initially, prior to undertaking the study, reliance on these alone is unsound and definitive conclusions cannot be made on these alone.

Thus, critics would argue that the real conclusion of the study is that fenoterol was used to treat patients with severe, unstable asthma who were likely to be at greater risk of death anyway. Although the methodological inconsistencies described certainly weaken the overall conclusion this study nevertheless runs in parallel with clinical work showing that long term treatment with $\beta_{2^{-}}$ agonists may be harmful in some situations.

\section{Drug treatment}

Advances in the drug treatment of asthma may be broadly divided into three groups. First, improvements in treating the acute attack; second, improvements in long term treatment and prophlyaxis and finally, areas of future drug development.

It is generally considered that ipratropium and cromoglycate are not 'first-line' treatments for adult acute asthmatics. Standard teaching has suggested that the former may have a role in those with chronic airflow limitation and the latter has a proven place in childhood asthma. However, recent studies do point to positive roles for these drugs in adult asthmatics.

In 56 patients with asthma and 47 with chronic obstructive pulmonary disease (COPD) in a double-blind protocol, $10 \mathrm{mg}$ nebulised salbutamol was compared to $10 \mathrm{mg}$ nebulised salbutamol plus $0.5 \mathrm{mg}$ nebulised ipratropium bromide. ${ }^{80}$ In asthmatics there was a $31 \%$ increase in peak expiratory flow rate (PEFR) with salbutamol but a $77 \%$ increase with salbutamol plus ipratropium. In patients with COPD there were small identical increases with both treatments. Although the $95 \%$ confidence intervals were wide $(8-84 \%)$ this does imply a useful benefit acutely and ipratropium has the additional advantage of a prolonged duration of action. ${ }^{81}$

Sodium cromoglycate may prove beneficial in older asthmatics as shown in a study in 77 patients over 50 years of age. Mean peak flow rate increased and inhaled $\boldsymbol{\beta}_{2}$ agonist use decreased considerably in one quarter of the patients studied. ${ }^{82}$

Management of chronic asthma remains a major clinical problem. Inhaled steroids are now the treatment of choice for asthma prophylaxis as opposed to using long term $\beta_{2}$-agonists. ${ }^{83}$ Moreover, high dose inhaled steroids decrease the requirement for oral steroids.

The systemic effects of inhaled steroids may produce adverse effects which are potentially serious. The hypothalamic-pituitary axis is significantly suppressed, growth may be affected and bone mass reduced but the exact clinical extent and relevance of such changes in the long term remains to be assessed. ${ }^{84}$ Dysphonia and oral candidiasis remain treatment complications at a rate of $5 \%$ or more.

In some patients, inhaled steroids are insufficient and the clinician may have to resort to systemic administration. Minimizing side effects may be achieved by alternate day dosage, repeated attempts to taper dosages and co-prescription of inhaled steroids. ${ }^{85}$ However, despite these manoeuvres the search for steroid sparing agents continues. Agents tried with variable success include gold salts and troleanomycin (a macrolide antibiotic). More recent work has focussed on low dose methotrexate $(15 \mathrm{mg} /$ week $)$ which in a double-blind study caused a $37 \%$ reduction in requirement for prednisolone in 14 patients as compared to placebo over 24 weeks. ${ }^{86}$ Larger, longer term studies are required to confirm its benefit and demonstrate its longterm efficacy and safety.

In conclusion, the concern over $\beta_{2}$-agonists has led to a shift in treatment prophylaxis towards routine use of inhaled steroids. The cost implications of this trend will require further consideration. Moreover, we may be soon approaching a point where steroid sparing agents may be routinely used. ${ }^{87}$ For severe attacks, $\beta_{2}$-agonists should probably be supplemented with ipratropium. The value of assessing each patient's responsiveness to inhaled medication by monitoring changes in PFR at the bedside is always worth emphasizing.

In the future, the major areas of drug development will probably focus on manipulation of two relatively recently described physiological systems controlling airways diameter and flow - those of platelet activating factor (PAF) and vasoactive intestinal polypeptide (VIP).

PAF is a phospholipid which acts as a potent inflammatory mediator, eliciting a long lasting increase in bronchial reactivity in both animals and man and increasing the microvascular permeability of guinea-pig airways. Furthermore, it is able to 
cause an eosinophilic infiltrate into alveoli. ${ }^{88}$ In animal studies, the increased bronchial reactivity and eosinophilic infiltration can be inhibited by a PAF antagonist ${ }^{89}$ The precise relevance of PAF is uncertain however. Although PAF can cause a bronchoconstrictor response in asthmatics it does not increase bronchial hyper-responsiveness. ${ }^{90}$ Moreover, it is questionable whether targetting drugs specifically against one of many mediators will prove of significant benefit in the long term.

VIP is a 28 amino acid peptide which is normally present in those pulmonary neurones responsible for bronchial smooth muscle relaxation. ${ }^{91}$ In a recent pathological study of 5 patients with asthma, none of 468 sections stained positive for intraneuronal, immunoreactive VIP as against $92 \%$ positivity in 9 controls with other forms of chronic lung disease. ${ }^{92}$ Furthermore, it has been demonstrated previously that VIP given by aerosol does reduce the severity of bronchial hyper-responsiveness by protecting against histamine-induced bronchoconstriction. ${ }^{93}$ Further clinico-pathological studies are awaited but if this is a primary phenomenon in asthma as opposed to a secondary effect, treatment based on VIP replacement may offer a significant therapeutic advance.

\section{Gastroenterology}

Gastroenterological therapeutics has witnessed the development of a number of new drugs whose place in treatment remains to be assessed. Of particular significance is the development of peptide analogues to both investigate and provide new potential treatments for gastrointestinal disease.

\section{Peptic ulcer disease}

The production of further $\mathrm{H}_{2}$-receptor antagonists (nizatidine and famotidine) has not added greatly to the existing members of this group..$^{94}$ Furthermore, with the recent launch of omeprazole (specifically indicated for duodenal and gastric ulceration unresponsive to adequate doses of conventional treatment and the Zollinger-Ellison syndrome) refractory peptic ulcers may now be treated with far greater ease.

Though recommended as a treatment for refractory peptic ulceration it is clear that omeprazole accelerates healing when compared to $\mathbf{H}_{2}$ antagonists in both duodenal and gastric ulcers. . $^{95,96}$ Moreover, it is of proven efficacy in ulcerative reflux oesophagitis. In a study of 196 patients, omeprazole $(40 \mathrm{mg}$ ) healed $81 \%$ of lesions compared to $6 \%$ in the placebo group. ${ }^{97}$ However, the rate of relapse was high: $82 \%$ by 6 months, and this was not influenced by smoking status. In addition, omeprazole is able to cause regression of Barrett's oesophagus with an 18 month course of treatment. ${ }^{98}$

Non-steroidal anti-inflammatory drugs (NSAID)induced gastroduodenal damage may also be treated successfully. Ninety five per cent of healing of gastric ulcers occurs with an 8 week treatment regimen of omeprazole $(40 \mathrm{mg} /$ day $)$ which is significantly better than ranitidine $(53 \%$ with $300 \mathrm{mg} /$ day). ${ }^{96}$

Relapse following treatment with omeprazole remains a problem. Continued daily long term administration is contraindicated since animal studies show that chronic dosing may cause gastric ECL (enterochromaffin like) cell hyperplasia and carcinoids. An alternative would be to use pulses of treatment for 3 days a week. This has been evaluated in 8 patients in remission following treatment of a duodenal ulcer. ${ }^{99}$ Omeprazole $20 \mathrm{mg} /$ day for 3 days per week was used for 2 months at the end of which there was a reduction in acid secretion by over $50 \%$. This is encouraging and a trial examining relapse rates with this 'weekend' therapy is needed. Compliance may be expected to be a major problem outside of a structured clinical trial protocol.

Misoprostil, a new prostaglandin analogue, is now available specifically for protecting against NSAID-induced gastroduodenal damage. ${ }^{100}$ This consists predominantly of gastric erosions and ulceration. Misoprostil prevents gastric damage but not duodenal lesions. Superficially this appears to be a major advance in protecting against NSAID-induced mucosal damage. There are a number of concerns however.

First, the important complications of gastric ulceration are haemorrhage and perforation and no evidence exists showing misoprostil reduces these. Second, misoprostil has no effect on duodenal lesions and this is important since in at least one study the 2 month prevalence with NSAID of duodenal ulcer was $8 \%$ and gastric ulcer $6 \% .^{101}$ At least half of the lesions would therefore be unaltered by misoprostil. Thirdly, misoprostil is no better than placebo at preventing pain. Finally, up to one half of patients are symptomless but these also need to be treated to prevent complications developing. The question of how one identifies this population is at present unknown. Clearly the precise indications for the drug are far from certain. In those requiring an NSAID who develop a gastric ulcer, misoprostil may be appropriate for healing. However, whether this will actually prevent serious morbidity is as yet unanswered.

There is currently a renewed interest in antacid therapy in peptic ulcer disease. Aluminiumcontaining antacids are not simply acid neutralizing agents but also have a mucosal protective role via stimulation of prostaglandin synthesis. ${ }^{102}$ This enables them to prevent, for example, alcohol 
induced gastric mucosal damage. ${ }^{103}$ Moreover, they may be useful as a low cost maintenance therapy to prevent duodenal ulcer relapse. Maalox contains aluminium hydroxide and magnesium hydroxide and in 251 patients with healed duodenal ulcers was found to reduce relapse to $23 \%$ at one year compared to $37 \%$ on placebo. ${ }^{104}$ This compared favourably to cimetidine $400 \mathrm{mg}$ nocte $(25 \%)$. This benefit was independent of smoking status.

Figure 1 demonstrates current treatment options for peptic ulcer disease. $\mathrm{H}_{2}$-antagonists remain the first line therapy, ranitidine being favoured in men (gynaecomastia with cimetidine) or in those on drugs metabolized by cytochrome P450 oxidase systems (inhibited by cimetidine).

In future, treatment strategies may need to be based on a better understanding of the role of Helicobacter pylori. This organism has aroused considerable interest and probably plays an important part in the tendency for healed ulcers to relapse. In future, the use of bismuth compounds, antibiotics or other drugs capable of eliminating this organism may become part of the regimen for treating peptic ulcers.

\section{Inflammatory bowel disease}

The major advances in management of inflammatory bowel disease have been in new ways of delivering the active moiety of sulphasalazine - 5 amino salicyclic acid (5.ASA) - to the colon thereby removing the side effects of the sulphonamide component.

Mesalazine (delayed release 5.ASA) is proven to be superior to sulphasalazine in maintenance treatment of colitis (at doses of 2-4 g/day) when assessed by sigmoidoscopic appearance of rectal mucosa and rectal bleeding. ${ }^{105}$ This preparation releases 5.ASA into the colon where the $\mathrm{pH}$ rises above 7.7. Other studies confirm its equal efficacy in maintenance therapy in ulcerative colitis with fewer side effects. ${ }^{106,107}$ 4-ASA is cheaper and may provide an alternative since in 10 patients with colitis 4-ASA has proved useful for symptomatic control using an open protocol. ${ }^{108}$

Olsalazine consists of two molecules of 5-ASA joined by an azo bond. Double-blind studies have confirmed its efficacy in ulcerative colitis in remission as compared to sulphasalazine, with relapse rates of $19.5 \%$ on olsalazine and $12.2 \%$ on sulphasalazine (not significant) over a 6 month period. ${ }^{109}$ Moreover, as a treatment for the first attack of distal colitis it is as effective as sulphasalazine, as shown in 37 patients who tolerated olsalazine better than sulphasalazine. ${ }^{110}$

Finally, methotrexate may have value as a steroid sparing agent in both ulcerative colitis and Crohn's disease. ${ }^{111}$ This study was completed in 21 patients using an open protocol. Their chronic inflammatory bowel disease had been refractory to other forms of therapy. In addition, cyclosporin A is emerging as a potentially safe form of immunomodulatory treatment though, again, use outside of properly designed trials cannot yet be recommended. Continued studies are required.

\section{Motility disturbance}

Cisapride is a novel prokinetic agent which appears to promote upper gastrointestinal motility. Two recent studies confirm its value in different clinical areas. In a study on morphine-induced delay on gastric emptying prior to surgery in $\mathbf{4 0}$ patients, cisapride $10 \mathrm{mg}$ intramuscularly reversed the effects of morphine more effectively than metoclopramide. ${ }^{112}$ It may therefore prove useful in preventing aspiration during general anaesthesia.

In a further study of 26 patients, treatment for 6 weeks with $10 \mathrm{mg}$ three times a day produced a significant increase in gastric emptying and antral motility together with normalization of manometrically measured oesophageal pressures (11 patients with diabetic gastroparesis and 15 with chronic idiopathic pseudo-obstruction). ${ }^{113}$

The place of this drug remains to be clarified in

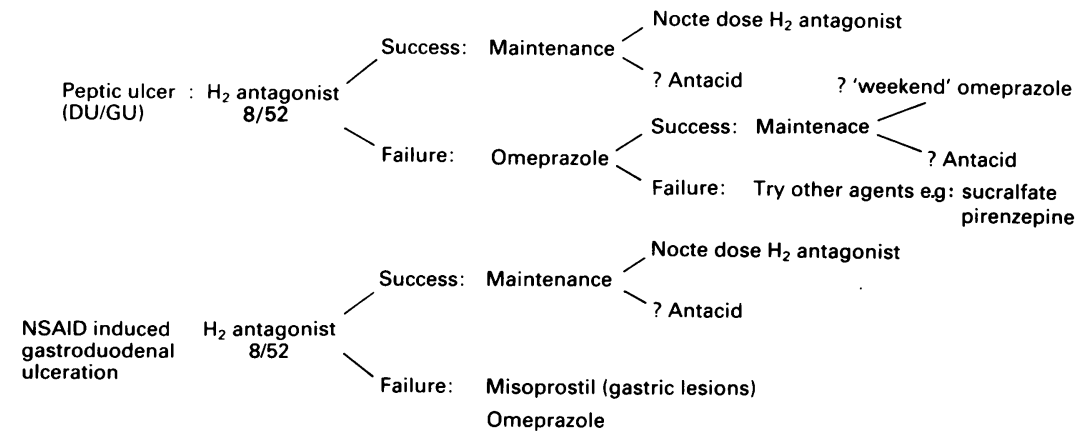

Figure 1 Strategy for ulcer disease 
patients with symptomatic reflux oesophagitis. However, cisapride is proven to increase lower oesophageal sphincter pressure in patients with reflux ${ }^{114}$ and there was a significant improvement in healing versus placebo when combined with cimetidine as opposed to cimetidine alone. ${ }^{116}$

\section{Hepatic encephalopathy}

Hepatic encephalopathy is thought to represent a state where there is an increase in an endogenous benzodiazepine. This is demonstrated by both increased serum and cerebrospinal fluid (CSF) benzodiazepine activity. ${ }^{117}$ It is postulated that this endogenous benzodiazepine binds to a specific allosteric binding site on the $\mathrm{GABA}_{\mathrm{A}}$ receptor thereby facilitating GABAergic synaptic transmission and provoking an encephalopathic state. Standard treatment of a low protein diet, lactulose and neomycin often fails to alleviate encephalopathy and a direct approach via inhibition of the endogenous benzodiazepine ligand has been proposed.

In an open, uncontrolled study of the benzodiazepine antagonist, flumazenil, in 17 patients with encephalopathy secondary to both acute and chronic liver failure, a $60 \%$ benefit in clinical state was observed (12 out of 20 episodes of encephalopathy remitting). ${ }^{118}$ Moreover, this clinical resolution was correlated to improvement in more objective measures of cerebral functioning, e.g. visual evoked potentials.

Flumazenil may therefore represent the first direct treatment of hepatic encephalopathy. Its problems are twofold. First, it has a short duration of action. However, a study of an oral preparation of flumazenil, $25 \mathrm{mg}$ twice daily for 14 months successfully prevented recurrence of the encephalopathic state though termination of treatment during this period saw a rapid return. ${ }^{11}$ This clinical improvement was also parallelled with normalization of evoked potentials. Secondly, although it may reverse the encephalopathic state it does not alter the underlying disease process leading to this state.

\section{Peptides}

Peptides are found extensively within the gastrointestinal tract and although they have been shown to have multiple effects on secretion, cell growth, blood flow and motility, an integrated understanding of their function is lacking. This poor understanding of their precise physiological importance makes evaluation of their contribution to pathophysiology even more difficult to assess.

However, information is becoming available on their role in disease processes and this allows for rational design of trials to investigate the therapeutic value of these peptides. Furthermore, peptides have potent in vivo effects which may be independently of value in treatment.

Somatostatin (or rather, its long acting analogue, octreotide administered subcutaneously) is the only peptide currently available for general use. Its specific indications are for relief of symptoms of carcinoid tumours, VIPomas and glucagonomas. However, its value in secretory ${ }^{120}$ and ileostomy diarrhoea ${ }^{121}$ is proven and its roles in acute variceal haemorrhage ${ }^{122}$ (reducing portal tributary blood flow in animal models of portal hypertension) and acute pancreatitis ${ }^{123}$ (the first clinical trial showed promising benefits on limiting pancreatic inflammation and abscess formation) remain to be clarified. Furthermore, animal studies show that somatostatin can reduce growth of implanted human colon adenocarcinoma cell lines. ${ }^{124}$

Cholecystokinin (CCK) antagonists have proven benefit in acute pancreatitis ${ }^{125}$ and limit the trophic effects of CCK on pancreatic adenocarcinoma cells ${ }^{126}$ in animal models. Clinical studies are available, however, only on motility regulation. The specific CCK antagonist, loxiglumide, significantly increased gastric emptying and shortened colonic transit time. ${ }^{127}$ It may therefore represent a useful prokinetic agent. Moreover, it is reported to prevent biliary colic. ${ }^{128}$ In 6 patients who developed colic following extracorporeal shock wave lithotripsy for gallstones, all 6 reported pain relief within 20 minutes of taking a single oral dose.

Metabolic correction of the sodium retaining state in ascites may be reversible with the vasopressin analogue, ornipressin, which in 9 patients with decompensated alcoholic cirrhosis and impaired renal function, improved creatinine clearance and promoted sodium excretion. ${ }^{129}$ The hyperdynamic state was also normalized and therefore in patients with decompensated cirrhosis with sympathetic activation, vasoconstrictor agents may be of use.

Finally, peptides have demonstrated new insights into pathophysiological processes which may or may not have therapeutic potential. For example, VIP appears to be an essential neurotransmitter at the internal anal sphincter and in studies in patients with idiopathic chronic constipation significant reductions in smooth muscle VIP content are found. ${ }^{130}$ Clearly this area will grow in future years as another route for pharmacological manipulation.

\section{Non-steroidal anti-inflammatory drugs}

It has always been appreciated that NSAIDs cause indigestion and sometimes ulceration and bleeding from the upper gastrointestinal (GI) tract. More recently reappraisal of their adverse effects ${ }^{131}$ par- 
ticularly on the gastrointestinal tract, on the kidney, on fluid and electrolyte balance and even on articular cartilage suggests that prolonged administration to patients with relatively mild disorders which lack a major inflammatory component may do more harm than good. This may be particularly true of the elderly.

\section{NSAID and the kidney}

NSAIDs may be responsible for a number of different renal disorders but at least four have been relatively clearly defined ${ }^{132}$ though they are probably interrelated.

\section{Haemodynamically induced renal dysfunction}

Prostaglandins probably play a relatively minor role in the functioning of the kidneys of normal individuals who are fully hydrated. However, under certain circumstances such as volume depletion, heart failure and some forms of renal disease, in which renal perfusion may be expected to be reduced, hormonal mechanisms are stimulated to provoke vasoconstriction and fluid retention. ${ }^{132,133}$ In these situations angiotensin II and noradrenaline constrict the renal arteries and aldosterone and antidiuretic hormone work to 'restore' blood volume. Since vasoconstriction may impair renal function these hormones also provoke prostaglandin (PG) production. These, specifically $\mathrm{PGE}_{2}$ and $\mathrm{PGI}_{2}$, dilate some intrarenal arteries and help to maintain renal function. NSAIDs which impair PG production may therefore leave uncompensated intra-renal vasoconstriction leading to renal dysfunction.

Based on the above explanation it is possible to predict that when renal perfusion is normal or near normal, NSAIDs will not adversely affect renal function. On the other hand elderly patients, those on diuretics, or those with renal vascular disease, diabetes, coronary artery disease or heart failure may be at risk if they are on an NSAID at a time of reduced renal artery perfusion for whatever cause. If this happens urine output falls, serum urea and creatinine rise. This may be reversed if the NSAID is stopped otherwise persisting renal damage may result.

\section{Drug interactions and fluid retention}

The numerous effects of PGs on fluid and electrolyte balance are not fully understood. The net result of their actions is to produce sodium, potassium and fluid loss. The mechanisms involve efferent arterial vasodilatation which reduces intraglomerular pressure leading to a reduction in the amount of fluid filtered and an increase in volume and decrease in osmotic pressure in the efferent arteriole. This leads to reduced salt and water reabsorption from the proximal tubule. ${ }^{132}$ Other PG-mediated effects include alterations in relative blood flow to cortex and medulla, and effects on the actions of $\mathrm{ADH} \cdot{ }^{132} \mathrm{~A}$ drug which impairs PG formation may therefore be expected to cause salt and water retention. It follows that NSAIDs will tend to counteract the actions of diuretics and antihypertensive drugs.

Considerable interest has been focussed on the question of whether renal PG inhibiting potency will predict renal effects. In particular, does sulindac, a NSAID with minimal PG inhibiting effects, have less unwanted effects on the kidney? ${ }^{133}$ There is evidence that it is safer and that it is not different. Certainly care is required to ensure that comparable doses of sulindac and a comparative drug are given, that the patients studied are in a state in which they require intra-renal PG production and that measurements of PGs truly reflect intra-renal PG status. On balance when all factors are considered it does seem that sulindac may have less effect on renal PGs and therefore on renal function but the evidence is not overwhelming.

\section{Interstitial nephritis}

This is believed to be a relatively infrequent complication of NSAID therapy which is characterized histologically by marked interstitial inflammatory changes and minimal change glomerulopathy. It has been suggested that NSAIDs in some way act as an allergen, interact with $\mathrm{T}$ lymphocytes and that there is a release of lymphokines. The clinical and pathological features of the disease are explained by the production of pro-inflammatory leukotrienes and by an increase in vascular permeability. ${ }^{134}$

Interstitial nephritis has been associated with fenoprofen and other propionic acid derivatives in particular and seems more likely to occur in older patients and those with underlying renal disease. ${ }^{132}$

\section{Analgesic nephropathy}

This disorder has been known for many years. Initially it was recognized that it tended to occur in certain parts of the world more than others, it was more common in females, and the cause seemed to be an excessive intake of analgesic mixtures. Further study suggested than phenacetin was the main cause and therefore this drug was withdrawn in most countries. The role of phenacetin as a cause of renal failure has been confirmed quite recently in a study from North Carolina. ${ }^{135}$ Interestingly, they also showed that a regular intake of acetaminophen (paracetamol), which is the major metabolite of phenacetin may be a cause of renal damage. ${ }^{135}$ An earlier study did not confirm a 
relationship between paracetamol intake and analgesic nephropathy but did raise the possibility that it might cause ureteric cancer. ${ }^{136}$ Clearly the effects of paracetamol need to be monitored carefully as the tendency to use simple analgesics more frequently gains momentum. It is of interest that phenacetin alone has not been shown to produce analgesic nephropathy whilst large doses of aspirin (though not low doses daily aspirin ${ }^{137}$ ) have been shown to be nephrotoxic and other NSAIDs are associated with this syndrome. The association with analgesic mixtures perhaps particularly those containing caffeine is intriguing, ${ }^{137}$ in part the adverse effects of mixtures may relate to the capacity of aspirin to deplete renal glutathione levels. ${ }^{138}$ Analgesic nephropathy remains an important cause of chronic renal failure. ${ }^{137}$

From the above it is apparent that NSAIDs may produce a number of different renal disorders and should be considered as a possible cause in any patient on these drugs who shows deteriorating renal function or who presents with unexplained renal failure. The problem is to see the relationship of NSAID intake in perspective. For the nephrologist NSAID may appear to be an important cause of kidney disease, the rheumatologist occasionally sees patients with renal dysfunction and is aware of the problem whereas the general practitioner knows that there are vast numbers of patients on NSAIDs who benefit from their actions and he or she has never seen a patient who has developed renal failure or nephrotic syndrome. The conclusion must be that all prescribers of NSAIDs must be aware of the risk of renal complications, know which types of patient are likely to be at greater risk and be ready to withdraw NSAIDs at the first sign of renal involvement. In addition, the known renal effects must be seen as sufficiently important as to argue against the widespread and chronic use of NSAID when they are not really indicated and when simple analgesics may be equally effective.

\section{Lesions of the upper gastrointestinal (GI) tract}

It is widely accepted that NSAIDs are potentially damaging to the upper GI tract. This observation has provoked a large number of questions and a rather smaller number of answers. Hazleman ${ }^{139}$ summarizes the problem as far as the United Kingdom is concerned. There are 23 million prescriptions for NSAIDs each year which is about $5 \%$ of the total NHS prescriptions. Of these, 12 million are for patients over 60 years of age. They account for $25 \%$ of all adverse reaction reports to the Committee on Safety of Medicines and many of them are for gastrointestinal haemorrhage. About $60 \%$ report dyspepsia. In England it has been estimated that NSAIDs may cause 400 deaths per year.
For the clinical pharmacologist the problems caused by NSAIDs on the GI tract pose a number of interesting questions. These include firstly how should this problem be evaluated, secondly what is the cause of the adverse effects and thirdly having considered the methods available and the results obtained can a simple message for the prescriber be provided.

In a review of this subject, Carson and Strom ${ }^{140}$ suggest that there are four main methods of assessing the adverse effects of NSAIDs on the upper gastrointestinal tract. These are animal studies, microbleeding studies, gastroscopic assessment and epidemiological studies. Data from drugs applied topically on to the gastric mucosa need to be interpreted with caution if inferences about human patient problems are to be drawn. This method will not be considered further.

Microbleeding studies assess bleeding in the gut before and during NSAID therapy by measuring ${ }^{51} \mathrm{Cr}$ labelled red cells in the stools. This has certain aesthetic disadvantages and suffers from the fact that ${ }^{51} \mathrm{Cr}$ is excreted in the bile and bile flow may be stimulated by aspirin and perhaps by related compounds. Further there is not a clear relationship between microbleeding detected in this way and clinically relevant gastrointestinal bleeding. In addition the difficulty of performing these studies tends to mean that the number of patients involved is relatively small and the duration of therapy relatively short. Information on NSAID gastropathy derived from microbleeding studies is therefore limited.

Endoscopic studies may require the patients to undergo upper GI endoscopy before starting NSAIDs and during treatment. This prospect makes these investigations seem uninviting to the patient and poses the question how long after starting therapy and how often need the endoscopy be repeated. An alternative approach is to compare the NSAID intake of those found at endoscopy to have an ulcer with controls who are shown not to have an ulcer. This method of assessment will only yield relevant information if peptic ulcer disease and NSAID gastropathy are essentially the same disorder (which they are possibly not) ${ }^{141}$ and if the control and disease group were comparable except for NSAID intake.

Epidemiological methods include post-marketing surveillance, case reports or small series, case control studies, cohort studies and randomized clinical trials. Studies without adequate controls may highlight the occurrence of possible adverse effects but these observations need to be confirmed and quantitated. However, even relatively well controlled studies may give misleading results if follow-up is incomplete, if recall about drug intake is defective or if other possible causes of gastropathy are not carefully documented and included in 
the assessment.

In 1986 Somerville and colleagues ${ }^{142}$ organized a case control study to investigate the possible relationship between NSAID intake and bleeding from peptic ulcers in London, England. The cases were patients over the age of 60 with a proven bleeding gastric or duodenal ulcer. The hospital controls were age and sex matched patients without peptic ulcers admitted to hospital on the same medical intake. In addition there was a community based control group consisting of age and sex matched patients who were next on an alphabetical list of the same general practitioner. This study showed that those with a bleeding ulcer were 2.7-3.8 times more likely to be taking NSAID than the controls.

A subsequent study by Carson and colleagues ${ }^{143}$ used a computerized data base on patients in Michigan and Minnesota to compare the risk of GI bleeding in 47,136 patients exposed to NSAID and 44, 634 unexposed patients. Those exposed had a $1.5(95 \%$ confidence limit $1.1-1.9)$ times risk of having an upper GI bleed. Ulcer perforations which have been increasing particularly in older women have also been linked with NSAID intake. $^{144,145}$

Recent reviews of these and other studies ${ }^{139,146}$ have considered the data presented and the potentially confounding factors. The conclusions which may be drawn are as follows: (1) NSAIDs probably do cause an increased rate of upper GI bleeding and perforation, though not all studies support this belief. (2) Serious complications are relatively infrequent and figures such as one bleed from about 6,500 prescriptions and one perforation for every $30-50,000$ prescriptions are quoted. (3) Because such large numbers of NSAIDs are prescribed their impact on the total problem of GI bleeds and perforations is considerable, particularly in elderly females, who are a group more likely to be taking these drugs.

The second question about NSAID gastropathy is - what is the mechanism and how may this influence treatment? It then becomes important to decide on the rival merits of increasing prostaglandin activity and/or reducing gastric acidity - a discussion which has considerable commercial implications which have an impact on the funding of studies and the publication of results in supplements. This subject has been reviewed by Rainsford. ${ }^{147}$ What emerges is that the inhibition of prostaglandin cyclo-oxygenase is an important consideration, that a large number of biochemical consequences, including an effect on gastric acid secretion, follow from this but that other perhaps less well known factors such as an inhibitory effect on high energy phosphates may play a part. In addition a recent report suggests a possible role for Helicobacter pylori. ${ }^{148}$

The third question is what should the prescriber do in relation to an increasing knowledge on the gastrotoxic effects of NSAIDs. Clearly the risk is so small that no single doctor will be aware of any benefits to be derived from reducing the number of NSAIDs prescribed and his or her patients may suffer a great deal more pain. However, the community will benefit and lives will be saved if (a) doctors are well aware of the problem, (b) NSAIDs are used to treat patients in whom a definite anti-inflammatory action is required, i.e. not if a simple analgesic could be used, and (c) care is taken in relation to prescribing for those who may be susceptible which means the ulcer or indigestion prone and perhaps the older female patient. Unfortunately, good data on the impact of smoking, other drugs, a history of indigestion and on the nature of the disease which is being treated, is lacking. It also seems difficult to produce evidence on the potential benefits of taking the drug after food or with alkali, of using enteric coated preparations or suppositories. All these manoeuvres might be considered prudent if a NSAID is required by someone who is prone to get upper GI symptoms.

\section{Lower gastrointestinal tract}

The effects of NSAIDs on the small intestine have also created some interest recently. ${ }^{149}$ These drugs may modify gut permeability allowing the mucosa to become exposed to bacterial degradation products and other toxins. ${ }^{150}$ This may explain the increased risk of perforations and strictures and the tendency to provoke quiescent inflammatory bowel disease into activity. ${ }^{151}$

NSAID-induced enteropathy poses a number of problems. These include firstly trying to define the mechanisms more precisely other than to confirm the role of reduced prostaglandin formation. Secondly the incidence of this disorder needs to be determined and to make this possible better ways of making a positive diagnosis need to be found. In the meantime the prescriber and the gastroenterologist must be aware of the possible role of NSAID in provoking small bowel dysfunction and disease.

\section{NSAIDs and articular cartilage}

The possibility that NSAIDs might have a significant impact on cartilage structure and function has provoked considerable interest in the last few years. ${ }^{152-154}$ In view of the large volume of sales, the commercial impact of being able to show that some members of this group were chondroprotective whilst others were chondro-destructive would be enormous. At the moment this seems a possibility rather than a proven fact.

A full understanding of the possible effects of drugs on cartilage requires a knowledge of its 
molecular structure, how it maintains its water content and the role of a variety of enzymes in its maintenance and destruction. Descriptions of these have been written ${ }^{153,154}$ and drug companies who think they have a chondro-protective drug usually have relatively easy-to-understand literature with helpful coloured pictures.

The non-expert needs to approach the subject with a clear head and a little scepticism. It is easy to accept that protein degrading enzymes and a corresponding group of inhibitors may be influenced directly and indirectly by prostaglandins, inflammatory cells and other mediators of inflammation. However, designing and performing studies to assess the impact of drugs and any active metabolites at appropriate concentrations in living human cartilage is difficult. In spite of the difficulties a number of studies have shown that some drugs modify the activity of various proteinases, ${ }^{155-157}$ cathepsin $B_{1}$ or elastase ${ }^{158,159}$ whereas others do not. Relating the results of such studies to the aetiology of osteoarthritis or coming to conclusions about the possible helpful effects of particular drugs requires caution. Nevertheless, in one recent study the potentially damaging effect of potent PG inhibition was demonstrated in relation to osteoarthritis of the hip. ${ }^{160}$

The NSAID prescriber could not yet base his or her choice of drug on the known effects of the compound on cartilage. ${ }^{161}$ Nevertheless it is important that there is an increasing awareness of this work and that we should take the result of research in this area very seriously.

\section{Alternative medicine}

Over the past decade, as individuals have wished to take a more active role in their choice of treatment within the overall health care system, there has been a move away from orthodox medicine to complementary techniques. These therapies are largely not validated by conventional standards and there have been recent attempts - notably in France - to subject them to randomized controlled trials to assess their true efficacy. This is a difficult area to test scientifically however, since one cannot simply exclude the psychotherapeutic benefit of an holistic approach to the patient and so interpretation has to be made with caution. The major areas of interest in alternaive medicine are diet, hypnotherapy, acupuncture and homeopathy.

Dietary therapy as the primary means of controlling disease, for example cancer, is advocated to the exclusion of all other therapy in the macrobiotic diet. This is a high carbohydrate, low fat diet with no animal food sources. One study ${ }^{162}$ has found a beneficial effect, as would be predicted, on reducing plasma lipids but there was also evidence of increased weight loss and protein-calorie malnutrition, clearly adverse effects in cancer patients. For those who may combine a macrobiotic diet with more conventional treatment of potential significance was the finding that drugs dependent on mixed function oxidase systems have a reduced clearance on such a diet. This may cause potential toxicity in the patient on drugs dependent on such degradative metabolic pathways.

Hypnotherapy has recently been evaluated in preventing duodenal ulcer relapse. Treatment of duodenal ulcers is not a therapeutic problem in most cases but up to $85 \%$ of patients may relapse following a course of $\mathrm{H}_{2}$-antagonists. Colgan et al. in an open, controlled trial followed 30 patients with endoscopically proven duodenal ulcer. ${ }^{163}$ Fifteen were allocated to hypnotherapy (initially 7 sessions with a home tape and subsquently at 3 monthly intervals) and 15 to placebo. Re-endoscopy at 12 months found recurrence in all 15 in the control group but only $8(53 \%)$ in the hypnotherapy group. In addition, hypnotherapy has long been regarded as a useful treatment in irritable bowel syndrome. Recently an $85 \%$ success rate has been reported in 200 patients. ${ }^{164}$

Acupuncture theory depends upon lines of energy (meridians) which flow through the body. If these become 'out of step' they may be normalized by needle stimulation into precise anatomical locations which is maintained by manual rotation. An alternative is acupressure over the same points. The evidence of benefit in the suppression of nausea and vomiting following general anaesthesia, postcytotoxic chemotherapy and in pregnancy is striking and an American group have recently shown benefit in severe alcoholism. ${ }^{165}$ Eighty patients were studied in a placebo-controlled protocol. Forty received acupuncture at specific treatment points while 40 received acupuncture in non-specific areas. In the control group there was a greater desire for alcohol, more drinking episodes and more admissions for detoxification as compared to the treated group.

Homeopathy spans herbal medicine and the homeopathy based on the 'Simillimum' principle. The latter means using small quantities of drugs which in healthy people induce the symptoms which they resolve in ill patients. Feverfew represents a herbal preparation advocated for the treatment of migraine. The scientific justification for this is that feverfew can inhibit serotonin release from platelets ${ }^{166}$ and serotonin is thought to be important in the aetiology of migraine. Seventy two patients were included in a randomized crossover study of feverfew versus placebo in preventing attacks and reducing symptoms of migraine. There was a significant reduction in the number of attacks (424 vs 559) and vomiting (42 events vs 78 events). No side effects were documented. ${ }^{167}$ 
The philosophical tenets of modern therapeutics have been seriously challenged by a study from a French group showing that human basophil degranulation occurred using an IgE antiserum at a dilution where there was calculated to be no possibility of any IgE remaining in the solution. ${ }^{168}$ They proposed that the water lattice itself may hold a 'memory' of the IgE which is chemically active. Though contradicted by a supposed independent group of reviewers the paper stands as a landmark linking orthodox medical research to complementary medical techniques. The therapeutic potential, however, remains to be proven. Mayaux et al. found no significant effects of a specifically indicated homeopathic preparation - opium and raphanus - in the time to recovery of bowel function in post-operative ileus. ${ }^{169}$ Furthermore, although a statistically significant result was obtained in a study of a preparation for treatment of influenza-like symptoms the result was hardly clinically relevant. Of 237 patients on treatment, 39 $(17.1 \%)$ recovered within a 48 hour period as against 24 of $241(10.3 \%)$ in the placebo group. ${ }^{170}$ Definition of influenza-like symptoms included pyrexia, headache, stiffness, arthralgia and shivers. However, Rhus toxicodendron (leaves from poison oak) at a dilution of $10^{-12}$ was assessed in a randomized double-blind protocol in 30 patients with fibrositis. ${ }^{171}$ There was a significant improvement in mean number of tender points and number of patients with improved pain and sleep (assessed by visual analogue scores) when compared to placebo.

Of any treatment we may reasonably ask, does it work and is it safe? While it is true that apart from the macrobiotic diet, no adverse effects have been found from other treatments one must be aware of the possibility. Examples are comfrey tea as a cause of hepatic veno-occlusive disease ${ }^{172}$ and the Department of Health warning on dietary supplements containing germanium.

The benefits of most forms of alternative medicine in the setting of a scientific trial seem unconvincing apart possibly from acupuncture. Other work remains to be confirmed. The benefit achieved may be as much from the attentive, holistic approach of the physician as of the medication per se. Nevertheless, only an open, unprejudiced mind will allow the true place of these therapies to be accurately assessed. Therefore the recent trend towards scientific assessment of what seems like less scientific methods of treatment is to be welcomed. It is of interest to note the relative lack of papers in this area.

\section{Acknowledgement}

We thank Mrs J. Bourne for her skill and patience in typing the manuscript.

\section{References}

\section{Cardiovascular therapeutics}

Heart failure

1. Horton, R.C. \& Kendall, M.J. Aspirin in the next decade. $J$ Clin Pharm Ther 1989, 14: 249-261.

2. Fleg, J.L., Gottlieb, S.H. \& Lakatta, E.G. Is digoxin really important in the treatment of compensated heart failure. Am $J$ Med 1982, 73: 244-250.

3. Cohn, J.N., Tristani, F.E. \& Khatri, I.M. Cardiac and peripheral vascular effects of digitalis in clinical cardiogenic shock. Am Heart J 1969, 78: 318-324.

4. Moss, A.J., Davis, H.J., Conrad, D.L., Decamilla, J.J. \& Odoroff, C.L. Digitalis associated cardiac mortality after MI. Circulation 1981, 64: 1150-1156.

5. Gillis, R.A. \& Quest, J.A. The role of the nervous system in the cardiovascular effects of digitalis. Pharmacol Rev 1979 , 31: 19-97.

6. Gheoghiade, M., St. Clair, J., St. Clair, C. \& Reller, G. Haemodynamic effects of intravenous digoxin in patients with severe heart failure initially treated with diuretics and vasodilators. J Am Coll Cardiol 1987, 9: 849-857.

7. Captopril-Digoxin Multicentre Research Group. Comparative effects of therapy with captopril and digoxin in patients with mild to moderate heart failure. JAMA 1988 , 259: 539-544.

8. German \& Austrian Xamoterol Study Group. Double-blind placebo controlled comparison of digoxin and xamoterol in chronic heart failure. Lancet 1988, i: 489-493.

9. Guyatt, G.H., Sullivan, M.J.J., Fallen, E.L. et al. A controlled trial of digoxin in congestive heart failure. $\mathrm{Am} \mathrm{J}$ Cardiol 1988, 61: 371-375.
10. Dibianco, R., Shabetai, R., Kostuk, W., Moran, J., Schlant, R.C. \& Wright, R. A comparison of oral milrinone, digoxin and their combination in the treatment of patients with chronic heart failure. $N$ Engl J Med 1989, 320: 677-683.

11. Editorial. Enoximone. Lancet 1988, i: 1085-1086.

12. Dreyfus, G., Abry, B., Jebara, V. et al. Enoximone as alternative to mechanical support while awaiting cardiac transplantation. Lancet 1989, i: 153.

13. Pouleur, H., Eyll, C.V., Hanet, C., Cheron, P., Charlier, A.A. \& Rousseau, M.F. Long term effects of xamoterol on left ventricular diastolic function and late remodeling. Circulation 1988, 77: 1081-1089.

14. Rousseau, M.F., Pouleur, H. \& Vincent, M.F. et al. Effects of a cardioselective $\beta_{2}$ partial agonist on left ventricular function and myocardial metabolism in patients with previous MI. Am J Cardiol 1983, 51: 1267-1274.

15. The Consensus Trial Study Group. Effects of enalapril on mortality in severe congestive heart failure. $N$ Engl J Med 1987, 316: 1429-1435.

16. Cohn, J.N., Archibald, D.G., Ziesch, S. et al. Effect of vasodilator therapy on mortality in chronic congestive heart failure. Results of a Veterans Administration Co-operative Study. N Engl J Med 1986, 314: 1547-1552.

17. Pfeffer, M.A., Lamas, G.A., Vaughan, D.E., Pardi, A.F. \& Braunwald, E. Effect of captopril on progressive ventricular dilatation after anterior myocardial infarction. $N$ Engl $J$ Med 1988, 319: 80-85. 
18. Cleland, J.G.F., Dargie, M.J., Hodsman, G.P. et al. Captopril in heart failure: a double blind controlled trial. Br Heart $J$ 1984, 54: 530-535.

19. Gilst, W.H., Graeff, P.A., Wesseling, H. \& Laneen, C.D.J. Reduction of reperfusion arrhythmias in the ischaemic isolated rat heart by ACE inhibitors: a comparison of captopril, enalapril and HOE498. J Cardiovasc Pharmacol 1986, 8: $722-728$.

20. Chopra, M., Scott, N., McMurray, J. et al. Captopril: a free radical scavenger. Br J Clin Pharmacol 1989, 27: 396-399.

21. Bagchi, D., Prasad, R. \& Das, D.K. Direct scavenging of free radical by captopril, an $\mathrm{ACE}$ inhibitor. Biochem Biophys Res Commun 1989, 158: 52-57.

22. McMurray, J., Chopra, M., McLay, J., Scott, N., Bridges, A. \& Belch, J. Free radical activity in chronic heart failure and effect of captopril. Br Heart J 1989, 61: 457-458.

23. Schrier, R.W. Pathogenesis of sodium and water retention in high output and low output cardiac failure, nephrotic syndrome, cirrhosis and pregnancy. $N$ Engl J Med 1988, 319: 1065-1072.

24. Northridge, D.B., Jardine, A.G., Alabaster, C.T. et al. Elevation of plasma atrial natriuretic factor by an atriopeptidase inhibitor has beneficial acute effects in mild heart failure. Lancet 1989, ii: 591-593

25. Editorial. Digoxin: new answers; new questions. Lancet 1989, ii: $79-80$.

\section{Lipid lowering agents}

26. Editorial. Primary prevention of ischaemic heart disease with lipid lowering drugs. Lancet 1988 , i: $333-334$

27. Illingworth, D.R. Lipid lowering drugs: an overview of indications and optimum therapeutic use. Drugs 1987, 33: 259-279.

28. Grundy, S.M. HMG-CoA reductase inhibitors for treatment of hypercholesterolaemia. $N$ Engl J Med 1988, 319: 24-33.

29. Tobert, J.A. New developments in lipid lowering therapy: the role of inhibitors of hydroxymethyl glutaryl-coenzyme A reductase. Circulation 1987, 76: 534-538.

30. Hoeg, J.M. \& Brewer, H.B. 3 Hydroxy-3-methyl glutarylcoenzyme A reductase inhibitors in the treatment of hypercholesterolaemia. JAMA 1987, 258: 3532-3536.

31. Erkelens, D.W. Apolipoproteins in lipid transport: an impressionist view. Postgrad Med J 1989, 65: 275-281.

32. Martin, M.J., Hulley, S.B., Browner, W.S., Kuller, L.H. \& Wentworth, D. Serum cholesterol, blood pressure and mortality: implications from a cohort of 361,662 men. Lancet 1986, ii: 933-936.

33. Frick, M.H., Elo, O., Haapa, K. et al. Helsinki Heart Study: primary prevention trial with gemfibrozil in middle-aged men with dyslipidaemia. $N$ Engl $J$ Med 1987, 317: 1237-1245

34. Study Group, European Atherosclerosis Society. The recognition and management of hyperlipidaemia in adults: a policy statement of the European Atherosclerosis Society. Eur Heart J 1988, 9: 571-600.

35. Editorial. Secondary prevention of coronary disease with lipid lowering drugs. Lancet 1989, i: 473-474.

36. Shankar, R., Sallis, J.D., Stanton, H. \& Thomson, R. Influence of probucol on early experimental atherogenesis in hypercholesterolaemic rats. Atherosclerosis 1989, 78:91-97.

37. Fears, R. Mode of action of lipid lowering drugs. In: Bailliere's Clinical Endocrinology and Metabolism, vol. 3. Bailliere Tindall, London, 1987, pp 727-754.

38. Lipid Research Clinics Program. The lipid research clinics coronary primary prevention trial results II. The reduction in incidence of coronary heart disease. JAMA 1984, 251: $351-362$.

39. Oliver, M.F., Heady, J.A., Morris, J.N. et al. A cooperative trial in the primary prevention of ischaemic heart disease using clofibrate: a report from the committee of principal investigators. Br Heart $J$ 1978, 40: 1069-1118.
40. Manninen, V., Elo, O., Frick, H. et al. Lipid alterations and decline in the incidence of coronary heart disease in the Helsinki Heart Study. JAMA 1988, 260: 641-651.

41. Canner, P.L., Berge, K.G., Wenger, N.K. et al. Fifteen year mortality in coronary drug project patients: long term benefit with niacin. J Am Coll Cardiol 1986, 8: 1245-1255.

\section{Hormone replacement therapy}

42. Belchetz, P. Hormone replacement treatment - deserves wider use. $\mathrm{Br}$ Med J 1989, 298: 1467-1468.

43. Ross, R.K., Pike, M.C., Henderson, B.E., Mack, T.M. \& Lobo, R.A. Stroke prevention and oestrogen replacement therapy. Lancet 1989, i: 505.

44. Ginsburg, J., Hardiman, P. \& O'Reilly, B. Peripheral blood flow in menopausal women who have hot flushes and in those who do not. Br Med J 1989, 298: 1488-1490.

45. Nogelovitz, M. Post menopausal osteoporosis. Acta Obstet Gynaecol Scand Suppl 1986, 134: 67-80.

46. Hammond, C.B. \& Maxson, W.S. Estrogen replacement therapy. Clin Obstet Gynecol 1986, 29: 407-430.

47. Weiss, N.S., Ure, C.L., Ballard, J.H., Williams, A.R. \& Daling, J.R. Decreased risk of fractures of the hip and lower forearm with post menopausal use of estrogen. $N$ Engl J Med 1980, 303: 1195-1198.

48. Munk-Jensen, N., Nielsen, S.P., Obel, E.B. \& Eriksen, P.B. Reversal of post menopausal vertebral bone loss by oestrogen and progestogen: a double blind placebo controlled study. Br Med J 1988, 296: 1150-1152.

49. Ettinger, B., Genane, H.K., Cann, C.E. Long term oestrogen replacement therapy prevents bone loss and fractures. Ann Intern Med 1985, 102: 319-324.

50. Whitehead, M.I. \& Fraser, D. Controversies concerning the safety of estrogen replacement therapy. Am J Obstet Gynecol 1987, 156: $1313-1322$.

51. Ziel, H.K. \& Finkle, W.D. Increased risk of endometrial carcinoma among users of conjugated estrogens. $N$ Engl $J$ Med 1975, 293: 1167-1170.

52. Mack, T.M., Pike, M.C., Henderson, B.E., Pfeffer, R.I., Gerkins, V.R. \& Arthur, M. Estrogens and endometrial cancer in a retirement community. $N$ Engl J Med 1976, 294: 1262-1267.

53. Brinton, L.A., Hoover, R. \& Fraumeni, J.F. Menopausal oestrogens and breast cancer risk: An expanded case-control study. $B r J$ Cancer 1986, 54: 825-832.

54. Bergkvist, L., Adami, H.O., Persson, I., Hoover, R. \& Schairer, $\mathrm{C}$. The risk of breast cancer after oestrogen and oestrogen-progestin replacement. $N$ Engl J Med 1989, 321: 293-297.

55. Gambrell, R.D., Maier, R.C. \& Sanders, B.I. Decreased incidence of breast cancer in postmenopausal oestrogenprogestogen users. Obstet Gynecol 1983, 62: 435-443.

56. Stadel, B.V. Oral contraceptives and cardiovascular disease - parts one and two. $N$ Engl J Med 1980, 305: 612-618, 672-677.

57. Wilson, P.W.F., Garrison, R.J. \& Castelli, W.P. Postmenopausal estrogen use, cigarette smoking and cardiovascular morbidity in women over 50: the Framingham Study. $N$ Engl J Med 1985, 313: 1038-1043.

58. Burch, J.C., Byrd, B.F. \& Vaughan, W.K. The effects of long term estrogen on hysterectomised women. Am J Obstet Gynecol 1974, 118: 778-782.

59. Ross, R.K., Pagannini-Hill, A., Mack, T.M. et al. Menopausal estrogen therapy and protection from death from ischaemic heart disease. Lancet 1981, i: 858-860.

60. Hammond, C.B., Jelovser, F.R., Lee, K.L. et al. Effects of long term estrogen replacement therapy. I Metabolic effects. Am J Obstet Gynecol 1979, 133: 525-536

61. Bush, T.L., Cowan, L.D., Barrett-Connor, E. et al. Estrogen use and all cause mortality. JAMA 1983, 249: 903-906.

62. Stampfer, M.J., Willett, W.S., Colditz, J.A. et al. A prospective study of postmenopausal estrogen therapy and coronary heart disease. $N$ Engl J Med 1985, 313: 1044-1049. 
63. Bush, T.L., Barrett-Connor, E., Cowan, L.D. et al. Cardiovascular mortality and non-contraceptive use of estrogen in women: results from the lipid research clinics program follow up study. Circulation 1987, 75: 1102-1109.

64. Petitti, D.B., Perlman, J.A. \& Sidney, S. Noncontraceptive estrogens and mortality: Long term follow up of women in the Walnut Creek Study. Obstet Gynecol 1987, 70: 289-293.

65. Grughow, H.W., Anderson, A.J., Barboriak, J.J. \& Soboginski, K.A. Postmenopausal use of estrogen and occlusion of coronary arteries. Am Heart $J$ 1988, 115: 954-963.

66. Thompson, S.G., Meade, T.W. \& Greenberg, G. The use of hormonal replacement therapy and the risk of stroke and myocardial infarction in women. $J$ Epidemiol Commun Health 1989, 43: 173-178.

67. Wahl, P., Walden, C., Knapp, R. et al. Effect of oestrogen/ progestin potency on lipid/lipoprotein cholesterol. $N$ Engl J Med 1983, 308: 862-867.

68. Barnes, R.B., Roy, S. \& Lobo, R.A. Comparison of lipid and androgen levels after conjugated estrogen or depomedroxyprogesterone acetate treatment in menopausal women. Obstet Gynecol 1985, 66: 216-219.

69. Mashak, C.A. \& Lobo, R.A. Estrogen replacement therapy and hypertension. J Reprod Med 1985, 30 (Suppl. 10): 805-810.

70. Aylward, M., Maddock, J. \& Rees, P.L. Natural oestrogen replacement therapy and blood clotting. $\mathrm{Br} \mathrm{Med} J$ 1976, 1 : 220.

71. Notelovitz, M., Kitchens, C. Ware, M. et al. Combination estrogen and progestogen replacement therapy does not adversely affect coagulation. Obstet Gynecol 1983, 62: $596-600$.

72. Spellacy, W.N. Menopause, estrogen treatment and carbohydrate metabolism. In: Mishell, D.R., Jr. (ed.) Menopause: Physiology and Pharmacology. Year Book Medical publishers, Chicago/London, 1987, pp. 253-260.

\section{Asthma}

73. Jackson, R., Sears, M.R., Beaglehole, R. \& Rea, M.M International trends in asthma mortality: $1970-1985$. Chest 1988, 94: 914-919.

74. Mitchell, E.A. Editorial: Is current treatment increasing asthma mortality and morbidity. Thorax 1989, 44: 81-84.

75. Vathenen, A.S., Higgins, B.G., Knox, A.J., Britton, J.R. \& Tattersfield, A.E. Rebound increase in bronchial responsiveness after treatment with inhaled terbutaline. Lancet 1988 , i: $554-557$.

76. Crane, J., Platt, A., Jackson, R. et al. Prescribed fenoterol and death from asthma in New Zealand 1981-83: case control study. Lancet 1986, i: 917-922.

77. O’Donnell, T.V., Rea, H.H., Holst, M.H. \& Sears, M.R. Fenoterol and fatal asthma. Lancet 1989 , i: $1070-1071$.

78. Buist, A.S., Burney, P.G.J., Feinstein, A.R. et al. Fenoterol and fatal asthma. Lancet 1989, i: 1071

79. Pearce, N., Crane, J., Burgess, C., Beasley, R. \& Jackson, R. Fenoterol and asthma mortality. Lancet 1989, i: 1196-1197.

80. O'Driscoll, B.R., Horsley, M.G., Taylor, R.J., Chambers, D.K. \& Bernstein, A. Nebulised salbutamol with and without ipratropium bromide in acute airflow obstruction. Lancet 1989, i: $1418-1420$.

81. Higgins, R.M., Stradling, J.R. \& Lane, D.J. Should ipratropium bromide be added to $\beta$-agonists in treatment of acute severe asthma? Chest 1988, 94: 718-722.

82. Boldy, D. \& Ayres, J.G. Nedocromil sodium and sodium cromoglycate in patients over 50 years of age with reversible airflow obstruction. Thorax 1989, 44: 362P.

83. Editorial. Management of asthma in the community. Lancet 1989, ii: $199-200$.

84. Konig, P. Inhaled corticosteroids - their present and future role in the management of asthma. J Allergy Clin Immunol 1988, 82: $297-306$.
85. Cott, G.R. \& Cherniack, R.M. Steroids and "steroid sparing" agents in asthma. $N$ Engl J Med 1988, 318: 634-636.

86. Mullarkey, M.F., Blumenstein, B.A., Andrade, P., Bailey, G.A., Olason, I. \& Wetsel, C.E. Methotrexate in the treatment of corticosteroid dependent asthma. $N$ Engl $J$ Med 1988, 318: 603-605

87. Shiner, R.J. \& Geddes, D.M. Treating patients with asthma who are dependent on systemic steroids. Br Med J 1989, 299: 216-217.

88. Editorial. PAF antagonists in asthma. Lancet 1989, i: $592-593$

89. Coyle, A.J., Urwin, S.C., Page, C.P., Touvay, C., Villain, B. \& Braquet, P. Effect of the selective PAF antagonist BN 52021 on PAF and antigen induced bronchial hyperreactivity and eosinophil accumulation. Eur J Pharmacol 1988, 148: $51-58$

90. Chung, K.F. \& Barnes, P.J. Effects of platelet activating factor on airway caliber, airway responsiveness and circulating cells in asthmatic subjects. Thorax 1989, 44: $108-115$.

91. Laitinen, A., Partanen, M., Hervonen, A., Pelto-Huikko, M. \& Laitinen, L.A. VIPlike immunoreactive nerves in human respiratory tract: light and electron microscopic study. Histochemistry 1985, 82: 313-319.

92. Ollerenshaw, S., Jarvis, D., Woolcock, A., Sullivan, C. \& Scheibner, T. Absence of immunoreactive VIP in tissue from lungs of patients with asthma. $N$ Engl $J$ Med 1989, 320: $1244-1248$

93. Barnes, P.J. \& Dixon, C.M. The effect of inhaled VIP on bronchial reactivity to histamine in humans. Am Rev Res Dis 1984, 130: $162-166$

\section{Gastrointestinal therapeutics}

94. Editorial. Too many $\mathrm{H}_{2}$ antagonists. Lancet 1988 , i: $28-29$.

95. Archambault, A.P., Pare, P., Bailey, R.J. et al. Omeprazole versus cimetidine in duodenal ulcer healing and pain relief. Gastroenterology 1988, 94: 1130-1134.

96. Walan, A., Bader, J.P., Classen, M. et al. Effect of omeprazole and ranitidine on ulcer healing and relapse rates in patients with benign gastric ulcer. $N$ Engl J Med 1989, 320: 69-75.

97. Hetzel, D.J., Dent, J., Reed, W.D. et al. Healing and relapse of severe peptic oesophagitis after treatment with omeprazole. Gastroenterology 1988, 95: 903-912.

98. Deviere, J., Buset, M., Dumonceau, J.M., Rickaert, F. \& Cremer, M. Regression of Barrett's epithelium with omeprazole. $N$ Engl J Med 1989, 320: 1497-1498.

99. Hewson, E.G., Yeomans, N.D., Angus, P.W. et al. Effect of "weekend therapy" with omeprazole on basal and stimulated acid secretion and fasting plasma gastrin in duodenal ulcer patients. Gut 1988, 29: 1715-1720.

100. Graham, D.Y., Agrawal, N.M. \& Roth, S.H. Prevention of NSAID induced gastric ulcer with misoprostil: multicentre double blind, placebo controlled trial. Lancet 1988, ii: $1277-1279$.

101. Editorial. Misoprostol: Ulcer prophylaxis at what cost? Lancet 1988, ii: $1293-1294$.

102. Preclik, G., Stange, E.F., Gerber, K., Fetzer, G., Horn, H. \& Ditschuneit, H. Stimulation of mucosal prostaglandin synthesis in human stomach and duodenum by antacid treatment. Gut 1989, 30: 148-151.

103. Hollander, D. \& Tarnawski, A. Are antacids cytoprotective? Gut 1989, 30: 145-147.

104. Bardhan, K.D., Hunter, J.D., Miller, J.P. et al. Antacid maintenance therapy in the prevention of duodenal ulcer relapse. Gut 1989, 29: $1748-1754$. 
105. Riley, S.A., Mani, V., Goodman, M.T., Herd, M.E., Dutt, S. \& Turnberg, L.A. Comparison of delayed release 5aminosalicylic acid (mesalazine) and sulphasalazine as maintenance treatment for patients with ulcerative colitis. Gastroenterology 1988, 94: 1383-1389.

106. Mulder, C.J.J., Tytgat, G.N.J., Weterman, I.T. et al. Double blind comparison of slow release 5-aminosalicylic and sulphasalazine in remission maintenance in ulcerative colitis. Gastroenterology 1988, 95: 1449-1453.

107. Rachmilewitz, D. Coated mesalazine versus sulphasalazine in the treatment of active ulcerative colitis: a randomised trial. Br Med J 1989, 198: 82-86.

108. Sharma, M.P. \& Duphare, H.V. 4-aminosalicylic acid enemas for ulcerative colitis. Lancet 1989, i: 450.

109. Ireland, A., Mason, C.H. \& Jewell, D.P. Controlled trial comparing olsalazine and sulphasalazine for the maintenance treatment of ulcerative colitis. Gut 1988, 29: $835-837$.

110. Rao, S.S.C., Dundas, S.A.C., Holdsworth, C.D., Cann, P.A., Palmer, K.R. \& Corbett, C.L. Olsalazine or sulphasalazine in first attacks of ulcerative colitis? A double blind study. Gut 1989, 30: 675-679.

111. Kozarek, R.A., Patterson, D.J., Gelfand, M.D., Botoman, V.A., Ball, T.J. \& Wilske, K.R. Methotrexate induced clinical and histological remission in patients with refractory inflammatory bowel disease. Ann Intern Med 1989, 110: 353-356.

112. Rowbotham, D.J., Bamber, A. \& Minno, N.S. Comparison of the effect of cisapride and metoclopramide on morphine induced delay in gastric emptying. Br J Clin Pharmacol 1988, 26: $741-746$.

113. Camillers, M., Malagelada, J.R., Abell, J.L., Brown, M.L., Hench, V. \& Zinsmeister, A.R. Effect of six weeks of treatment with cisapride in gastroparesis and intestinal pseudoobstruction. Gastroenterology 1989, 96: 704-712.

114. Ceccatelli, P., Janssens, J., Vantrappen, G. \& Cucchiara, S Cisapride restores the decreased lower oesophageal sphincter pressure in reflux patients. Gut 1988, 29: 631-635.

115. Baldi, F., Porro, G.B. \& Obrilla, O. Cisapride versus placebo in reflux oesophagitis. A multicentre double blind trial. $J$ Clin Gastroenterol 1988, 10: 614-618.

116. Galmiche, J.P., Brandstasjfer, G., Eureux, M. et al. Combined therapy with cisapride and cimetidine in severe reflux oesophagitis: a double blind controlled trial. Gut 1988, 29: 675-681.

117. Olasmaa, M., Guidotti, A., Costa, E. et al. Endogenous benzodiazepines in hepatic encephalopathy. Lancet 1989, i: 491-492.

118. Grimm, G., Ferenci, P., Katzenschlager, R. et al. Improvement of hepatic encephalopathy treated with flumazenil. Lancet 1988, ii: $1392-1393$.

119. Ferenci, P., Grimm, G., Meryn, S. \& Gang, L. Successful long term treatment of portal-systemic encephalopathy by the benzodiazepine antagonist flumazenil. Gastroenterology 1989, 96: 240-243.

120. Jaros, W., Biller, J., Greer, S., Dorisio, J. \& Grand, R. Successful treatment of idiopathic secretory diarrhoea of infancy with the somatostatin analogue SMS 201-995. Gastroenterology 1988, 94: 189-193.

121. Williams, N.S., Cooper, J.C., Axon, A.T.R., King, R.F.G. \& Barker, M. Use of a long acting somatostatin analogue in controlling life threatening ileostomy diarrhoea. $\mathrm{Br} \mathrm{Med} \mathrm{J}$ 1984, 289: $1027-1028$.

122. Cerini, R., Braillon, A., Hadengue, A., Koshy, A., Lee, S.S \& Lebrec, D. Somatostatin anlogue improves survival in conscious cirrhotic rats subjected to gastrointestinal bleeding. Clin Sci 1989, 77: 7-9.

123. Choi, T.K., Mok, F., Zhan, W.H., Fan, S.T., Lai, E.C.S. \& Wong, G.J. Somatostatin in the treatment of acute pancreatitis: a prospective randomised controlled trial. Gut 1989, 30: 223-227.
124. Smith, J.P. \& Solomon, T.E. Effects of gastrin, proglumide and somatostatin on growth of human colon cancer. Gastroenterology 1988, 95: 1544-1548.

125. Silverman, M., Ilardi, C., Bank, S., Kranz, V. \& Lend, V.A.I. Effects of cholecystokinin receptor antagonist L364, 718 on experimental pancreatitis in mice. Gastroenterology 1989, 96: $186-192$.

126. Douglas, B.R., Woutersen, R.A., Jansen, J.B.M.J., Jong, A.J.L., Rovati, L.C. \& Lamers, C.B.H.W. Influence of cholecystokinin antagonist on the effects of cholecystokinin and bombesin on azaserine induced lesions in rat pancreas. Gastroenterology 1989, 96: 462-469.

127. Meyer, B.M., Werth, B.A., Beglinger, C. et al. Role of cholecystokinin in regulation of gastrointestinal motor functions. Lancet 1989, ii: 12-14.

128. Berlinger, C., Dill, S., Meyer, B., Werth, B. \& Adler, G Loxiglumide and biliary colic. Lancet 1989, ii: 167.

129. Lenz, K., Hortnagl, H., Oruml, W. et al. Beneficial effect of 8-ornithine vasopressin on renal dysfunction in decompensated cirrhosis. Gut 1989, 30: 90-96.

130. Koch, T.R., Carney, J.A., Go, L., \& Go, V.L.W. Idiopathic chronic constipation is associated with decreased colorin vasoactive intestinal peptide. Gastroenterology 1988, 94: $300-310$.

\section{NSAIDs}

131. Brooks, P.M. Side effects of non-steroidal drugs. Med J Aust 1988, 148: $248-251$

132. D'Angio, R.G. Nonsteroidal anti-inflammatory druginduced renal dysfunction related to inhibition of renal prostaglandins. Drug Int Clin Pharmac 1987, 21: 954-960.

133. Dunn, M.J., Simpson, M., Davidson, E.W., Scharschmidt, L.A. \& Sedor, J.R. Non steroidal anti-inflammatory drugs and renal function. J Clin Pharmacol 1988, 28: 524-529.

134. McCarthy, J.T., Schwartz, G.L., Blair, T.J., Pierides, A.M. \& Van Dan Berg, C.J. Reversible non oliguric acute renal failure associated with Zomepirac therapy. Mayo Clin Proc 1982, 57: 351-354.

135. Sandler, D.P., Smith, J.C., Weinberg, C.R. et al. Analgesic use and chronic renal disease. $N$ Engl $J$ Med 1989, 320: $1238-1243$.

136. McCredie, M. \& Stewart, J.H. Does paracetamol cause urothelial cancer or renal papillary necrosis? Nephron 1988, 49: $286-300$.

137. Bennett, W.M. \& Debroe, M.E. Analgesic nephropathy - a preventable renal disease. $N$ Engl J Med 1989, 320: $1269-1271$.

138. Walkerm, R.J. \& Duggin, G.D. Drug nephrotoxicity. Ann Rev Pharmacol Toxicol 1988, 28: 331-345.

139. Hazleman, B.L. Incidence of gastropathy in destructive arthropathies. Scand J Rheumatol 1989. 78 (Suppl.): 1-4.

140. Carson, J.L. \& Strom, B.L. The gastrointestinal side effects of the nonsteroidal anti-inflammtory drugs. J Clin Pharmacol 1988, 28: 554-559.

141. Roth, S.H. \& Bennett, R.E. Non steroidal antiinflammatory drug gastropathy. Arch Intern Med 1987, 147: 2093-2100.

142. Somerville, K., Faulkner, G. \& Langman, M. Non steroidal anti-inflammatory drugs and bleeding peptic ulcer. Lancet 1986 , i: $462-464$.

143. Carson, J.L., Strom, B.L., Soper, K.A., West, S.L. \& Morse, L. The association of non steroidal anti-inflammatory drugs with upper gastrointestinal bleeding. Arch Intern Med 1987, 147: 85-88.

144. Walt, R., Katschinski, B., Logan, R., Ashley, J. \& Langman, M.J.S. Rising frequency of ulcer perforation in elderly people in the United Kingdom. Lancet 1986, i: 489-492.

145. Cockel, R. NSAIDs - should every prescription carry a Government Health warning. Gut 1987, 28: 515-518. 
146. Langman, M.J.S. Epidemiologic evidence on the association between peptic ulceration and anti-inflammatory drug use. Gastroenterology 1989, 96: 640-646.

147. Rainsford, K.D. Mechanisms of NSAID-induced gastrointestinal injury: a basis for preventing ulceration and symptoms from these agents. Aliment Pharmacol Therap 1988, 25: 43-55.

148. Iglehart, I.W., Edlow, D.W., Mills, L., Morrison, S.A. \& Hochberg, M.C. The presence of Campylobacter pylori in non steroidal anti-inflammatory drug associated gastritis. $J$ Rheumatol 1989, 16: 599-603.

149. Banerjee, A.K. Enteropathy induced by non-steroidal antiinflammatory drugs. Br Med J 1989, 298: 1539-1540.

150. Bjarnason, I., Zanelli, G., Smith, T. et al. The pathogenesis and consequence of non steroidal anti-inflammatory drug induced small intestinal inflammation in man. Scand $J$ Rheumatol 1987, 64 (Suppl.): 55-62.

151. Kaufmann, H.J. \& Taubin, H.L. Non steroidal antiinflammatory drugs activate quiescent inflammatory bowel disease. Ann Intern Med 1987, 107: 513-516.

152. Bjelle, A. NSAIDs and cartilage metabolism. Scand $J$ Rheumatol 1989, 77 (Suppl.): 43-52.

153. Brandt, K.D. Effects of non steroidal anti-inflammatory drugs on chondrocyte metabolism in vitro and in vivo. Am J Med 1987, 83 (Suppl 5A): 29-34.

154. Ghosh, P. Antirheumatic drugs and cartilage. Balliere's Clinical Rheumatology 1988, 2: 309-338.

155. Perper, R.J. \& Bronsky, A.G. Enzyme release from human leukocytes and degradation of cartilage matrix. Effects of antirheumatic drugs. Arthritis Rheum 1974, 17: 47-55.

156. Kruze, D., Dehr, K., Menninger, H. \& Bowi, A. Effect of antirheumatic drugs on neutral protease from human leucocyte granules. Rheumatol 1976, 35: 337-346.

157. Kruze, D., Dehb, K. \& Boni, A. Effect of antirheumatic drugs on cathepsin $B_{1}$ from bovine spleen. $Z$ Rheumatol 1976, 35: 95-102.

158. Stephens, R.W., Walton, E.A., Ghost, P. et al. A radioassay for proteolytic cleavage of isolated cartilage proteoglycan 2 . Inhibition of human leukocyte elastase and cathepsin $\mathrm{G}$ by anti-inflammatory drugs. Arzneimittel-Forschung 1980, 30: $2108-2112$

159. Lentini, A., Ternai, B. \& Ghost, P. Inhibition of human leucocyte elastase and cathepsin B by nonsteroidal antiinflammatory compounds. Biochem Int 1987, 15: $1069-1078$
160. Rashad, S., Revell, P., Hemingway, A., Low, F., Rainsford, K. \& Walker, F. Effect on non steroidal anti-inflammatory drugs on the course of osteoarthritis. Lancet 1989, ii: 519-521.

161. Jubb, R. Osteoarthritis - analgesics or non steroidals? J Clin Pharm Ther 1989, 14: 247-248.

\section{Alternative medicine}

162. Wissel, P.S., Denke, M. \& Intorrisi, C.E. A comparison of the effects of a macrobiotic diet and a western diet on drug metabolism and plasma lipids in man. Eur J Clin Pharmacol 1987, 33: 403-407.

163. Colgan, S.M., Faragher, E.B. \& Whorwell, P.J. Controlled trial of hypnotherapy in relapse prevention of duodenal ulceration. Lancet 1988, i: $1299-1300$.

164. Whorwell, P.J. Hypnotherapy in irritable bowel syndrome. Lancet 1989, i: 622.

165. Bullock, M.L., Culliton, P.D. \& Olander, R.T. Controlled trial of acupuncture for severe recidivist alcoholism. Lancet 1989 , i: $1435-1438$.

166. Heptinstall, S. Feverfew - an ancient remedy for modern times. J R Soc Med 1989, 81: 373-374.

167. Murphy, J.J., Heptinstall, S. \& Mitchell, J.R.A. Randomised double blind placebo controlled trial of feverfew in migraine prevention. Lancet 1988, ii: 189-192.

168. Darmas, E., Bravvais, F., Amara, J. et al. Human basophil degranulation triggered by very dilute antiserum against IgE. Nature 1988, 333: 816-818.

169. Mayaux, M.J., Moscato, M.L.G., Schwartz, D. et al. Controlled clinical trial of homeopathy in postoperative ileus. Lancet 1988, i: 528-529.

170. Farley, J.P., Zmirov, D., D'Adhemar, D. \& Balducci, F. A controlled evaluation of a homeopathic preparation in the treatment of influenza like symptoms. Br J Clin Pharmacol 1989, 27: $329-335$.

171. Fisher, P., Greenwood, A., Huskisson, E.C., Turner, P. \& Belan. P. Effect of homeopathic treatment on fibrositis (primary fibromyalgia). Br Med J 1989, 299: 365-366.

172. Ridker, P.M. \& McDermott, W.V. Comfrey herb tea and hepatic veno-occlusive disease. Lancet 1989, i: 657-658. 